\title{
20-Week follow-up of hepatic steatosis installation and liver mitochondrial structure and activity and their interrelation in rats fed a high-fat-high-fructose diet
}

\author{
Gilles Fouret ${ }^{1}$, Sylvie Gaillet ${ }^{1}$, Jerome Lecomte ${ }^{2}$, Beatrice Bonafos ${ }^{1}$, Ferdinand Djohan ${ }^{1,3}$, Bruno Barea ${ }^{2}$, \\ Eric Badia ${ }^{3}$, Charles Coudray ${ }^{1}$ and Christine Feillet-Coudray ${ }^{1 *}$ \\ ${ }^{1}$ DMEM, INRA, Univ. Montpellier, Montpellier, France \\ ${ }^{2}$ IATE, CIRAD, Montpellier, France \\ ${ }^{3}$ PhyMedExp, INSERM, Montpellier, France
}

(Submitted 12 July 2017 - Final revision received 8 November 2017 - Accepted 27 November 2017)

\section{Abstract}

The incidence of obesity and its metabolic complications are rapidly increasing and become a major public health issue. This trend is associated with an increase in the prevalence of non-alcoholic fatty liver disease (NAFLD), insulin resistance and diabetes. The sequence of events leading to NAFLD progression and mitochondrial dysfunction and their interrelation remains to be elucidated. This study aimed to explore the installation and progression of NAFLD and its association with the liver mitochondrial structure and activity changes in rats fed an obesogenic diet up to 20 weeks. Male Wistar rats were fed either a standard or high-fat-high-fructose (HFHFR) diet and killed on 4, 8, 12,16 and 20 weeks of diet intake. Rats fed the HFHFR diet developed mildly overweight, associated with increased adipose tissue weight, hepatic steatosis, hyperglycaemia and hyperinsulinaemia after 8 weeks of HFHFR diet. Hepatic steatosis and many biochemical modifications plateaued at 8-12 weeks of HFHFR diet with slight amelioration afterwards. Interestingly, several biochemical and physiological parameters of mitochondrial function, as well as its phospholipid composition, in particular cardiolipin content, were tightly related to hepatic steatosis installation. These results showed once again the interrelation between hepatic steatosis development and mitochondrial activity alterations without being able to say whether the mitochondrial alterations preceded or followed the installation/progression of hepatic steatosis. Because both hepatic steatosis and mitochondrial alterations occurred as early as 4 weeks of diet, future studies should consider these four 1 st weeks to reveal the exact interconnection between these major consequences of obesogenic diet intake.

Key words: Rats: High-fat-high-fructose diets: Hepatic steatosis: Mitochondrial activity: Phospholipids: Cardiolipin

The metabolic syndrome is defined by the presence of central obesity, non-alcoholic fatty liver disease (NAFLD), hyperlipidaemia, hyperglycaemia, insulin resistance (IR) and hypertension. In the developed countries, as well as in many developing countries, where food supplies are abundant and physical activity is reduced, the incidence of obesity is rapidly increasing and becomes a major public health problem $^{(1)}$. This trend is associated with a parallel increase in the prevalence of NAFLD, which affects about $30 \%$ of the general population in Western society, and is recognised as the most common cause of liver dysfunction worldwide ${ }^{(2-4)}$. Liver lipid accumulation (steatosis) is the first stage of NAFLD and can occur from the diet, from de novo lipogenesis or from lipids released from adipose tissue. It is a phenomenon that takes place rapidly when rats are submitted to high-fat feeding but that does not develop linearly over time ${ }^{(5)}$. In parallel, oxidative stress, inflammation, mitochondrial dysfunction and IR may lead to large hepatocyte injuries (steatohepatitis/cirrhosis), which characterise the second stage of NAFLD.

Accumulating and emerging evidence indicates that hepatic mitochondria play a critical role in the development and progression of steatosis and NAFLD, which is consistent with the major contribution of mitochondria in the fatty acid metabolism. Indeed, mitochondrial dysfunction and impaired mitochondrial electron transport chain have been described in many mouse/rat models of diet-induced obesity characterised by hepatic steatosis, liver injury and IR. Owing to the multiple functions performed by mitochondria, the term mitochondrial dysfunction is ambiguous. In relation with NAFLD, mitochondrial dysfunction refers to the impairment of mitochondrial electron transport chain function at respiratory complexes, as well as a reduction in mitochondrial oxidative phosphorylation and ATP synthesis.

Abbreviations: CHOL, cholesterol; CL, cardiolipin; CLS, CL synthase; HFHFR, high-fat-high-fructose; IR, insulin resistance; NAFLD, non-alcoholic fatty liver disease; PC, phosphatidylcholine; PE, phosphatidylethanolamine; ROS, reactive oxygen species; Tfam, mitochondrial transcription factor A; UI, unsaturation index.

* Corresponding author: Dr C. Feillet-Coudray, fax +33467545694, email christine.coudray@inra.fr 
Phospholipids are constituents of intracellular and extracellular cell membranes including both inner and outer mitochondrial membranes ${ }^{(6)}$. Mitochondrial phospholipids define the physical properties of mitochondrial membranes and might, therefore, be expected to regulate the activities of proteins of the electron transport chain, as well as ATP production. Prominent among mitochondrial phospholipids is cardiolipin (CL), which is predominantly localised in the mitochondrial inner membrane, at the heart of mitochondrial metabolism. CL is known to affect mitochondrial bioenergetics and also to contribute to mitochondrial membrane dynamics ${ }^{(7)}$. In fact, significant changes in CL content/ profile may alter the membrane fluidity and also the organisation and functioning of the mitochondrial respiratory chain complexes. Such alterations may in turn modify interactions between these complexes, leading to an altered mitochondrial production of reactive oxygen species (ROS) ${ }^{(8)}$. The content and/or composition of CL have been well documented in diverse pathological settings associated with mitochondrial dysfunction ${ }^{(9,10)}$, whereas few studies in the literature have described the possible changes in the CL content in the course of hepatic steatosis installation. For example, in NAFLD induced by choline-deficient diet, a decrease in the hepatic mitochondrial CL content was observed ${ }^{(11)}$. By contrast, in NAFLD induced by high-fat diet, an increase in the hepatic mitochondrial CL content was observed by our previous works ${ }^{(12)}$.

The present study was thus designed to explore the causal relationship and underlying mechanisms between NAFLD installation and progression and mitochondrial dysfunction in rats fed an obesogenic diet for 4-20 weeks, emphasising on the mitochondrial dysfunction and on the mitochondrial phospholipids alterations, in particular the CL. Determining whether the mitochondrial dysfunction precedes or follows the hepatic steatosis is an important health issue for the prevention or the treatment of this pathology. The strong point of our study is double in that, unlike most of the literature studies mentioned above, we have carried out several time points up to 20 weeks and we have carried out a control group and an high-fat-highfructose (HFHFR) group at each studied time point.

\section{Methods}

\section{Animals and diets}

In all, seventy-five young male Wistar rats (Charles River) were housed (two per cage) under conditions of constant temperature $\left(20-22^{\circ} \mathrm{C}\right)$, humidity $(45-50 \%)$ and a standard dark cycle $(20.00$ 08.00 hours). The rats were block-randomised to the different time points of killing at the beginning of the study into ten groups (five groups fed the control diet and five other groups fed the high-fat-high-fructose diet). This randomisation was based on the initial rat body weight. Rats fasted for $9 \mathrm{~h}$ (seven to eight rats per group) were killed after $4,8,12,16$ or 20 weeks on the control or the HFHFR diet.

The detailed composition of these two diets is given in the online Supplementary Table S1. The control diet contains $4 \%$ lipids as soyabean oil, and the HFHFR diet contains $35 \%$ lipids ( $1 \%$ soyabean oil $+8.5 \%$ lard $+17 \%$ palm oil $+8.5 \%$ cocoa butter) and $25 \%$ fructose. Refined palm oil (VAMOLINE) was purchased from Vandemoortele Lipids and Dough Division.
The lipid fraction of the control diet was composed of $17.4 \%$ SFA, $28.1 \%$ MUFA and $54.5 \%$ PUFA, and that of the HFHFR diet was composed of $44.2 \%$ SFA, $43.2 \%$ MUFA and $12.6 \%$ PUFA (for more information, see online Supplementary Table S2). Rats were given free access to food and tap water. Rat body weight was determined weekly and food consumption was determined every 2 or $3 \mathrm{~d}$. Our institution guidelines for the care and use of laboratory animals were observed and all experimental procedures were approved by the local ethics committee in Montpellier, France (reference CEEA-LR-12002).

\section{Oral glucose tolerance test}

The oral glucose tolerance test (OGTT) was completed 4-5d before killing the rats and performed as previously described ${ }^{(13)}$. Briefly, 6-h fasting rats (08.00 to 14.00 hours) received by oral administration $2.5 \mathrm{~g}$ glucose $/ \mathrm{kg}$ body weight. Blood was sampled through the tail vein of conscious rats immediately before the oral administration, and 20, 40, 60, 90, 120 and 180 min afterwards, and blood glucose was measured using glucose strips and a commercial glucometer (AccuChek Active; Roche Diagnostics). Total cumulative glucose levels for each treatment group are reported as AUC and was calculated by the trapezium method and expressed as g blood glucose/l per $180 \mathrm{~min}$.

\section{Sampling and routine biochemical analysis}

On $4,8,12,16$ and 20 weeks of diet intake, 4 to $5 \mathrm{~d}$ after the OGTT, 9-h-fasted rats (23.00-08.00 hours) were anaesthetised with pentobarbital ( $40 \mathrm{mg} / \mathrm{kg}$ body weight) and blood was drawn from the abdominal artery with slightly heparinised syringes, to prevent possible coagulation during the blood sampling, and distributed into dry and heparinised tubes. Blood tubes were centrifuged at $1000 \mathrm{~g}$ for $10 \mathrm{~min}$ at $4^{\circ} \mathrm{C}$, and plasma or serum were collected and stored at $-80^{\circ} \mathrm{C}$ until analysis. Liver was removed, rinsed with $0.9 \% \mathrm{NaCl}$ and cut into two parts: one part was divided into several aliquots and frozen in liquid $\mathrm{N}_{2}$ and kept at $-80^{\circ} \mathrm{C}$ until analyses, and one part was used for the immediate isolation of fresh mitochondria.

Plasma glucose, serum total cholesterol (CHOL), TAG, NEFA and alanine transaminase (ALAT) levels were measured by enzymatic techniques (Sobioda). Plasma insulin was quantified with ELISA kits (Merck Millipore; Invitrogen by ThermoFisher). IR was evaluated by the homoeostasis model of IR (HOMA-IR) formula: (plasma glucose level $(\mathrm{mm}) \times$ plasma insulin level $(\mathrm{mU} / \mathrm{l})) / 22 \cdot 5^{(14)}$.

\section{Liver neutral lipids analysis}

Liver samples were extracted with a mixture of chloroformmethanol $(2: 1, \mathrm{v} / \mathrm{v})$ according to Folch et $a l .{ }^{(15)}$ in the presence of $50 \mathrm{mg} / \mathrm{l}$ butylated hydroxytoluene to prevent lipid oxidation. Folch extracts were automatically applied on silica gel 60 highperformance TLC (HPTLC) plates $(250 \mu \mathrm{m}, 20 \times 10 \mathrm{~cm}$; Merck), pretreated with $1.5 \%(\mathrm{w} / \mathrm{v})$ boric acid in ethanol (100\%), on a $4-\mathrm{mm}$ band width using ATS4 apparatus (CAMAG). The development was performed first with methanol-pentanechloroform (3:52:45, by vol.), which allowed the separation of NEFA, CHOL and TAG + cholesteryl ester (TAG + CE) on a 
50-mm total migration distance and then with diethyl etherpentane $(3: 97, \mathrm{v} / \mathrm{v})$, which allowed the separation of TAG and $\mathrm{CE}$ on a $57-\mathrm{mm}$ total migration distance. The scanning of the plates was carried out using a TLC scanner 3 (CAMAG), operating in the reflectance mode. The plates were scanned at $550 \mathrm{~nm}$ after dipping in a solution of copper sulphate $\left(\mathrm{CuSO}_{4}-\right.$ $\mathrm{H}_{3} \mathrm{PO}_{4}-\mathrm{H}_{2} \mathrm{O}, 40 \mathrm{~g}: 20 \mathrm{ml}: 230 \mathrm{ml}$ by vol.) and heating for $20 \mathrm{~min}$ at $180^{\circ} \mathrm{C}$. The different classes of neutral lipids (NEFA, CHOL, TAG and CE) were finally identified by comparing their retention factor $\left(R_{\mathrm{f}}\right)$ with authentic standards and quantified using calibration curves of the same standards.

\section{Liver mitochondrial isolation}

Liver mitochondria were isolated from fresh liver by the differential centrifugation technique ${ }^{(16)}$. Briefly, about $3 \mathrm{~g}$ of liver were homogenised in 10 volumes of sucrose buffer (Sucrose $0.25 \mathrm{~m}$, TRIS $10 \mathrm{~mm}$, EDTA $0.5 \mathrm{~mm}, \mathrm{pH} 7.5$ ) and centrifuged at $900 \mathrm{~g}$ for $10 \mathrm{~min}$ at $4^{\circ} \mathrm{C}$. The supernatant was then centrifuged at $10000 \boldsymbol{g}$ for $10 \mathrm{~min}$ at $4^{\circ} \mathrm{C}$. The pellet was suspended in $3 \mathrm{ml}$ of Miro5 buffer ( $110 \mathrm{~mm}$ sucrose, $20 \mathrm{~mm}$ HEPES, $10 \mathrm{~mm} \mathrm{KH}_{2} \mathrm{PO}_{4}$, $20 \mathrm{~mm}$ taurine, $60 \mathrm{~mm}$ K-lactobionate, $3 \mathrm{~mm} \mathrm{MgCl}_{2} \cdot 6 \mathrm{H}_{2} \mathrm{O}, 0.5 \mathrm{~mm}$ ethylene glycol tetraacetic acid (EGTA), $1 \mathrm{~g} / 1$ bovine serum albumin, $\mathrm{pH} 7 \cdot 1$ ). One aliquot of the mitochondrial suspension was used for mitochondrial function measurement ${ }^{(13)}$. and one aliquot was frozen at $-80^{\circ} \mathrm{C}$ for lipid measurement. Protein content was determined according to Bradford with bovine serum albumin as the standard ${ }^{(17)}$.

\section{Mitochondrial characteristics and enzyme activities}

The liver mitochondrial membrane potential and ROS production were assessed as previously described ${ }^{(16,18)}$. Mitochondrial respiration was determined by measuring mitochondrial $\mathrm{VO}_{2}$ in a high-resolution Oxygraph (Oroboros Oxygraph $\left.{ }^{2 \mathrm{k}}\right)^{(16)}$. The enzymatic activity of citrate synthase (CS) in liver and mitochondrial respiratory complexes (complex I, complex II + III and complex IV) in liver mitochondria were determined spectrophotometrically as previously described ${ }^{(12)}$. Mitochondrial $\beta$-hydroxyacyl-CoA dehydrogenase ( $\beta$-HAD) activity, a marker of last step of mitochondrial $\beta$-oxidation activity, was determined spectrophotometrically according to the procedure described ${ }^{(19)}$. Briefly, liver mitochondria suspension $(25 \mu \mathrm{g}$ protein) was mixed with $\mathrm{NADH}$ and acetoacetyl CoA in $1 \mathrm{ml}$ of $50 \mathrm{~mm}$ TRIS-HCl buffer, $\mathrm{pH}$ $7 \cdot 0$, and absorbance was followed at $340 \mathrm{~nm}$ for $60 \mathrm{~s}$ at $30^{\circ} \mathrm{C}$.

\section{Separation and analysis of liver mitochondria phospholipids}

Liver mitochondrial suspensions were extracted using a mixture of chloroform-methanol (2:1; v/v) according to Folch et $a l .{ }^{(15)}$ in the presence of $50 \mathrm{mg} / \mathrm{l}$ of butylated hydroxytoluene to prevent lipid oxidation. Phosphorus was quantified on Folch extracts of mitochondrial suspensions in order to determine total phospholipid quantity as previously described ${ }^{(20)}$.

Folch extracts of mitochondrial suspensions were automatically applied on silica gel 60 HPTLC plates $(250 \mu \mathrm{m}, 20 \times 10 \mathrm{~cm})$, pretreated with $2.3 \%(\mathrm{w} / \mathrm{v})$ boric acid in ethanol (100\%), on a $4 \mathrm{~mm}$ band width using ATS4 apparatus (CAMAG). The lipid spots development was performed with methanol-acetic acidpentane-chloroform (15:10:30:45, by vol.), which allowed the separation of phospholipids and neutral lipids on a $60-\mathrm{mm}$ total migration distance. The scanning of the plates was carried out using a TLC scanner 3 (CAMAG), operating in the reflectance mode. The plates were scanned at $715 \mathrm{~nm}$ after dipping in a solution of Blue Spray (Sigma) (Blue Spray-4.2 $\mathrm{M} \mathrm{H}_{2} \mathrm{SO}_{4}$-acetone, 1:2:3, by vol.) and heating for $3 \mathrm{~min}$ at $55^{\circ} \mathrm{C}$. The different classes of phospholipids (sphingomyelin $=\mathrm{SM}$, lyso-phosphatidylcholine $=\mathrm{LPC}$, phosphatidylcholine $=\mathrm{PC}$, phosphatidylinositol $=\mathrm{PI}$, phosphatidylserine $=\mathrm{PS}$, phosphatidylethanolamine $=\mathrm{PE}$, phosphatidylglycerol $=\mathrm{PG}$, phosphatidic acid $=\mathrm{PA}, \mathrm{CL}$ ) were finally identified by comparing their $R_{\mathrm{f}}$ with authentic standards and quantified using calibration curves of the same standards.

\section{Fatty acid analysis of liver mitochondrial lipid extracts}

Liver mitochondrial lipid extracts were mixed with 12.5 $\mu \mathrm{g}$ C17:0, as an internal standard, and their fatty acids were esterified by addition of acidified methanol, according to the method of Lepage $\&$ Roy $^{(21)}$. Briefly, the methylation reagent was generated by mixing sulphuric acid with methanol and butylated hydroxytoluen as antioxidant $(50 \mathrm{mg} / \mathrm{l})$, and the sample was heated at $90^{\circ} \mathrm{C}$ for $45 \mathrm{~min}$ to obtain the fatty acid methyl esters. After addition of sodium bicarbonate, distilled water and hexane, the sample was vortexed, centrifuged and the upper hexane layer was transferred to a glass vial, evaporated under a nitrogen stream at $37^{\circ} \mathrm{C}$ and dissolved in $0.5 \mathrm{ml}$ isooctane-butylated hydroxytoluene for GC analysis. Individual fatty acid methyl esters were identified according to the retention times of standards by gas liquid chromatography (Trace GC Ultra; Thermo Fisher Scientific), with a Supelco Vax capillary column $(30 \mathrm{~m} \times 0.32 \mathrm{~mm}$ internal diameter $\times 0.25 \mu \mathrm{m} \mathrm{df}$ ), an AS-3000 autosampler and flame-ionisation detector. The fatty acid methyl esters were quantified using the chromatographic peak area according to the internal standard method. The fatty acid composition of mitochondrial lipids was compared in terms of the percentage content of various fatty acids.

\section{Liver lipid mitochondrial desaturase and unsaturation indices}

Because it is very difficult and tricky to directly measure the activity of the enzymes that catalyse the desaturation and elongation reactions in the fatty acid metabolic pathways, results in animals have supported the use of surrogate measures of desaturase activity such as the use of desaturase indices ${ }^{(22)}$. These indices are based on the ratio of product:precursor of individual fatty acids for a given desaturation reaction. The desaturase indices were thus calculated as follows: desaturase $\Delta 9(16: 1 n-7 / 16: 0)$; desaturase $\Delta 6$ (18:3n-6/18:2n-6); and desaturase $\Delta 5(20: 4(n-6) / 20: 3(n-6))$. The unsaturation index (UI) was calculated from the relative percentage of each type of MUFA and PUFA multiplied by the number of double bonds present in the molecule ${ }^{(12)}$.

\section{Immunoblotting for Western blot analysis}

Frozen liver samples were homogenised using an Ultra Turax homogeniser in an ice-cold extraction buffer containing $20 \mathrm{~mm}$ 
TRIS-HCl, $150 \mathrm{~mm} \mathrm{NaCl,} 1 \mathrm{~mm}$ EDTA, 0.5\% Triton X-100, 0.1\% SDS, $1 \mathrm{~mm}$ PMSF, $10 \mu \mathrm{m}$ leupeptin and $1 \mu \mathrm{m}$ pepstatin. Proteins $(50 \mu \mathrm{g})$ were separated with $10 \%$ SDS-PAGE and then transferred to a nitrocellulose membrane $(90 \mathrm{~min}, 120 \mathrm{~V})$. Membranes were blocked in 5\% fat-free milk for $1 \mathrm{~h}$ at room temperature. Then, membranes were incubated overnight with primary antibody against PPAR- $\gamma$ coactivator $1 \alpha$ (PGC1-a) (Calbiochem) and CL synthase (CLS) (Abcam) in blocking buffer. After washes in TRIS-buffered saline/Tween under gentle agitation, membranes were incubated for one hour with horseradish-peroxidase-labelled antibody. After further washes, blots were treated with enhanced chemiluminescence detection reagents (ECL; ThermoScientific). $\beta$-Tubulin was used as loading reference, and blot intensities were measured using Image $\mathrm{Lab}^{\mathrm{TM}}$ Software 5.2.1 (Bio-Rad Laboratories). This analysis was performed in five separate runs (a run per time point for control and HFHFR samples).

\section{Isolation of total RNA and real-time real-time quantitative $P C R$}

Real-time quantitative PCR (RT-qPCR) was used to measure target gene mRNA expression in liver. Total RNA was extracted with Trizol reagent (Invitrogen). Reverse transcription reaction was performed with $2 \mu \mathrm{g}$ of total RNA. Complementary DNA (cDNA) was synthesised with the use of SuperScript II Reverse Transcriptase for first-strand cDNA synthesis (Invitrogen) and Oligo (dT) primers. The mRNA expressions of target genes (CLS and mitochondrial transcription factor A (Tfam)) were determined by RT-qPCR, using IQTM SYBR Green Supermix with a MiniOpticon detection system (Bio-Rad). Results were expressed using the comparative cycle threshold $\left(C_{t}\right)$ method: the $\Delta \Delta C_{t}$ values were calculated in every sample for each gene of interest with RPS9 gene as the reference gene. The primer sequences used for realtime RT-PCR are the following: RPS9 forward GAAGCTGGG TTTGTCGCAAA, RPS9 reverse CGGAGCCCATACTCTCCAAT; CLS forward TGGATGGATTTATTGCTCGAAA, CLS reverse
TGGGACTGGAATAAGATCTGCAT, Tfam forward AATGAA GTCTTGGGAAGAGCAA, Tfam reverse ACACTGCGACGGAT GAGAT.

\section{Statistical analysis}

Results were expressed as means and standard deviations, six to eight animals per group per treatment duration. All the groups were tested for the effects of diet, treatment duration and their interaction by two-way ANOVA test. When the effects of diet, treatment duration or their interaction were significant, one-way ANOVA test was applied to analyse the effect of treatment duration for each diet followed up by a Fisher's least significant difference test, and the unpaired Student's $t$ test was used to analyse the effect of HFHFR diet within each treatment duration point. For protein expression results, the analysis was carried out time by time, and thus comparison among time points was not possible; therefore, comparison was then made only between control and HFHFR diets inside of each time point by the unpaired Student's $t$ test. The limit of statistical significance was set at $P<0 \cdot 05$. HFHFR diet $v$. control diet: $* P<0.05$, * $P<0.005, * * * 0<0005$. Inside the same diet, over treatment durations, the means with different letters (a, b, c, d, e) are significantly different. Correlations were performed with the Spearman method. Statistical analyses were performed using the StatView program (SAS Institute).

\section{Results}

\section{Rat characteristics and blood biochemical parameters}

Dietary intake and energy intake were increased throughout the study in both rat groups, whereas the dietary intake was largely lower with the HFHFR diet by comparison with the control diet, but with similar energy intake in both groups, although this energy intake was higher on 12 and 16 weeks of diet intake (Table 1). As expected, rat body weight, as well as liver and adipose tissue weights, were gradually increased throughout the study under both diets, but these increases were much

Table 1. Rat characteristics

(Mean values and standard deviations; $n 6-8$ animals/group per treatment duration)

\begin{tabular}{|c|c|c|c|c|c|c|c|c|c|c|c|c|c|c|}
\hline \multirow[b]{2}{*}{ Parameters } & \multirow[b]{2}{*}{ Diet } & \multicolumn{2}{|c|}{4 weeks } & \multicolumn{2}{|c|}{8 weeks } & \multicolumn{2}{|c|}{12 weeks } & \multicolumn{2}{|c|}{16 weeks } & \multicolumn{2}{|c|}{20 weeks } & \multirow[b]{2}{*}{ Time $(P)$} & \multirow[b]{2}{*}{ Diet $(P)$} & \multirow[b]{2}{*}{ Time $\times \operatorname{diet}(P)$} \\
\hline & & Mean & SD & Mean & SD & Mean & SD & Mean & SD & Mean & SD & & & \\
\hline \multirow[t]{2}{*}{ Dietary intake $(\mathrm{g} / \mathrm{d})$} & Control & $19 \cdot 1^{\mathrm{a}}$ & 0.3 & $19 \cdot 5^{\mathrm{a}}$ & 0.6 & $19 \cdot 3^{a}$ & 0.4 & $19 \cdot 9^{a}$ & 0.6 & $21 \cdot 4^{\mathrm{b}}$ & 0.9 & & & \\
\hline & HFHFR & $12 \cdot 2^{\star \star \star a}$ & $0 \cdot 1$ & $14 \cdot 1^{\star \star \star b}$ & 0.1 & $15 \cdot 0^{\star \star \star c}$ & 0.5 & $15 \cdot 1^{\star \star \star c}$ & 0.3 & $15 \cdot 3^{\star \star \star c}$ & 0.8 & $<0.0001$ & $<0.0001$ & 0.0002 \\
\hline \multirow[t]{2}{*}{ Energy intake $(\mathrm{kJ} / \mathrm{d})$} & Control & $308^{a}$ & 5 & $315^{\mathrm{a}}$ & 9 & $312^{a}$ & 7 & $321^{a}$ & 10 & $346^{\mathrm{b}}$ & 15 & & & \\
\hline & HFHFR & $273^{\star \star a}$ & 2 & $315^{\mathrm{b}}$ & 2 & $336^{\star c}$ & 11 & $337^{\star c}$ & 6 & $342^{c}$ & 18 & $<0.0001$ & NS & $<0.0001$ \\
\hline \multirow[t]{2}{*}{ Initial body wt (g) } & Control & 102 & 8 & 106 & 10 & 96 & 6 & 101 & 9 & 105 & 6 & & & \\
\hline & HFHFR & 102 & 9 & 105 & 3 & 99 & 9 & 101 & 6 & 103 & 11 & NS & NS & NS \\
\hline \multirow[t]{2}{*}{ Final body wt (g) } & Control & $276^{\mathrm{a}}$ & 21 & $362^{b}$ & 32 & $421^{c}$ & 41 & $471^{d}$ & 35 & $543^{e}$ & 53 & & & \\
\hline & HFHFR & $252^{\mathrm{a}}$ & 23 & $379^{\mathrm{b}}$ & 44 & $474^{\star c}$ & 40 & $517^{\star c, d}$ & 46 & $561^{d}$ & 60 & $<0.0001$ & 0.0300 & NS \\
\hline \multirow[t]{2}{*}{ Adipose tissue wt (g) } & Control & $9 \cdot 91^{\mathrm{a}}$ & 2.35 & $21.5^{\mathrm{b}}$ & $6 \cdot 1$ & $30 \cdot 3^{c, d}$ & 8.6 & $31 \cdot 2^{d}$ & 8.4 & $39 \cdot 1^{\mathrm{e}}$ & 7.7 & & & \\
\hline & HFHFR & $8.46^{a}$ & 1.48 & $26 \cdot 7^{b}$ & 8.0 & $48 \cdot 2^{\star \star c, d}$ & 8.5 & $49 \cdot 5^{\star \star d}$ & 12.4 & $58 \cdot 9^{\star \star \mathrm{e}}$ & 11.6 & $<0.0001$ & $<0.0001$ & 0.0013 \\
\hline \multirow[t]{2}{*}{ Liver wt (g) } & Control & $8.38^{\mathrm{a}}$ & 1.20 & $9 \cdot 71^{\mathrm{a}, \mathrm{b}}$ & 1.4 & $10 \cdot 8^{\mathrm{b}, \mathrm{c}}$ & 0.6 & $11 \cdot 7^{\mathrm{c}}$ & $1 \cdot 7$ & $13 \cdot 7^{d}$ & 1.9 & & & \\
\hline & HFHFR & $8.46^{\mathrm{a}}$ & 1.5 & $12 \cdot 0^{* \mathrm{~b}}$ & $2 \cdot 1$ & $15 \cdot 4^{\star \star \star c}$ & 1.9 & $15 \cdot 9^{\star \star c}$ & 3.3 & $17 \cdot 8^{\star c}$ & $4 \cdot 1$ & $<0.0001$ & $<0.0001$ & 0.0337 \\
\hline
\end{tabular}

HFHFR, high-fat-high-fructose.

All the groups were tested for the effects of diet, treatment duration and their interaction by two-way ANOVA test. When the effects of diet, treatment duration or their interaction were significant, one-way ANOVA test was applied to analyse the effect of treatment duration for each diet followed up by a Fisher's least significant difference test, and the unpaired Student's $t$ test was used to analyse the effect of HFHFR diet within each treatment duration point.

The limit of statistical significance was set at $P<0.05$. HFHFR diet $v$. control diet: ${ }^{*} P<0.05,{ }^{* *} P<0.005,{ }^{* * *} P<0.0005$.

$\mathrm{a}, \mathrm{b}, \mathrm{c}, \mathrm{d}, \mathrm{e}$ Inside the same diet, over treatment durations, mean values with unlike superscript letters are significantly different. 
Table 2. Metabolic plasma parameters

(Mean values and standard deviations; $n$ 6-8 animals/group per treatment duration)

\begin{tabular}{|c|c|c|c|c|c|c|c|c|c|c|c|c|c|c|}
\hline \multirow[b]{2}{*}{ Parameters } & \multirow[b]{2}{*}{ Diet } & \multicolumn{2}{|c|}{4 weeks } & \multicolumn{2}{|c|}{8 weeks } & \multicolumn{2}{|c|}{12 weeks } & \multicolumn{2}{|c|}{16 weeks } & \multicolumn{2}{|c|}{20 weeks } & \multirow[b]{2}{*}{ Time $(P)$} & \multirow[b]{2}{*}{$\operatorname{Diet}(P)$} & \multirow{2}{*}{$\begin{array}{c}\text { Time } \times \text { diet } \\
(P)\end{array}$} \\
\hline & & Mean & SD & Mean & SD & Mean & SD & Mean & SD & Mean & SD & & & \\
\hline \multirow[t]{2}{*}{ Glucose (g/l) } & Control & $1.62^{a}$ & 0.25 & $1.84^{\mathrm{b}, \mathrm{c}}$ & 0.16 & $2 \cdot 02^{c}$ & 0.19 & $1 \cdot 78^{\mathrm{a}, \mathrm{b}}$ & 0.15 & $1.96^{b, c}$ & 0.25 & & & \\
\hline & & $1.81^{\mathrm{a}}$ & 0.13 & $1.94^{\mathrm{a}}$ & 0.32 & $2 \cdot 25^{\star b}$ & 0.15 & $1.97^{* a}$ & 0.20 & $1.92^{\mathrm{a}}$ & 0.17 & $<0.0001$ & 0.0056 & NS \\
\hline \multirow[t]{2}{*}{ Insulin (ng/l) } & Control & $4.53^{\mathrm{a}}$ & $2 \cdot 39$ & $7 \cdot 84^{b, c}$ & 3.01 & $7.06^{\mathrm{b}}$ & $2 \cdot 19$ & $7 \cdot 86^{\mathrm{b}}$ & 1.81 & $10 \cdot 4^{c}$ & $2 \cdot 2$ & & & \\
\hline & $\begin{array}{l}\text { HFHFR } \\
\text { Control }\end{array}$ & $\begin{array}{r}3.90^{\mathrm{a}} \\
48.0^{\mathrm{a}}\end{array}$ & $\begin{array}{c}1.75 \\
29.5\end{array}$ & $\begin{array}{c}9.09^{\mathrm{b}, \mathrm{c}} \\
91.7^{\mathrm{b}}\end{array}$ & $\begin{array}{r}2.84 \\
36.9\end{array}$ & 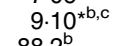 & 1.52 & $8.72^{b}$ & 1.30 & $11 \cdot 3^{c}$ & 3.4 & $<0.0001$ & 0.0453 & NS \\
\hline HOMA-IR & $\begin{array}{l}\text { Control } \\
\text { HFHFR }\end{array}$ & $\begin{array}{l}48 \cdot 0^{\mathrm{a}} \\
43.5^{\mathrm{a}}\end{array}$ & $\begin{array}{l}29.5 \\
21.5\end{array}$ & $\begin{array}{r}91.7^{\circ} \\
111^{\mathrm{b}}\end{array}$ & $\begin{array}{l}36 \cdot 9 \\
46\end{array}$ & $\begin{array}{r}88 \cdot 2^{b} \\
126^{\star \star b}\end{array}$ & $\begin{array}{l}33.4 \\
26\end{array}$ & $85 \cdot 4^{\mathrm{b}}$ & $19 \cdot 2$ & $126^{\mathrm{b}}$ & $\begin{array}{l}37 \\
55\end{array}$ & & & \\
\hline \multirow{3}{*}{$\begin{array}{l}\text { Cholesterol } \\
(\mathrm{mmol} / \mathrm{l}) \\
\text { TAG (mmol/l) }\end{array}$} & Control & $1 \cdot 16^{a}$ & 0.08 & $1.44^{\mathrm{a}, \mathrm{b}}$ & 0.29 & $1 \cdot 60^{\mathrm{b}, \mathrm{c}}$ & 0.23 & $1 \cdot 78^{\mathrm{c}, \mathrm{d}}$ & $\begin{array}{r}24 \\
0.31\end{array}$ & $1.96^{\mathrm{d}}$ & $\begin{array}{l}55 \\
0.49\end{array}$ & $<0.0001$ & 0.0362 & NS \\
\hline & $\begin{array}{l}\text { HFHFR } \\
\text { Control }\end{array}$ & $\begin{array}{l}1.32^{\mathrm{a}} \\
0.88^{\mathrm{a}}\end{array}$ & $\begin{array}{l}0.17 \\
0.31\end{array}$ & $\begin{array}{l}1.50^{\mathrm{a}} \\
1.05^{\mathrm{a}}\end{array}$ & $\begin{array}{l}0.21 \\
0.54\end{array}$ & $\begin{array}{l}1.54^{\mathrm{a}} \\
1.9^{\mathrm{a}, \mathrm{b}}\end{array}$ & 0.23 & $\begin{array}{l}1.67^{\mathrm{a}} \\
1.71^{\mathrm{b}}\end{array}$ & 0.31 & $\begin{array}{l}1.95^{\mathrm{b}} \\
1.47^{\mathrm{a}, \mathrm{b}}\end{array}$ & 0.21 & $<0.0001$ & NS & NS \\
\hline & $\begin{array}{l}\text { Control } \\
\text { HFHFR }\end{array}$ & $\begin{array}{l}0.83^{\mathrm{a}} \\
0.6\end{array}$ & $\begin{array}{l}0.31 \\
0.17\end{array}$ & $\begin{array}{l}1.05^{\mathrm{a}} \\
1.25^{\mathrm{b}}\end{array}$ & $\begin{array}{l}0.54 \\
0.67\end{array}$ & $\begin{array}{l}1.19^{\text {a,b }} \\
1.20^{b}\end{array}$ & $\begin{array}{l}0.43 \\
0.43\end{array}$ & $\begin{array}{l}1.71^{\mathrm{b}} \\
1.05^{\mathrm{b}}\end{array}$ & $\begin{array}{l}0.90 \\
0.33\end{array}$ & $\begin{array}{l}1.47^{\mathrm{a}, \mathrm{b}} \\
1.18^{\mathrm{b}}\end{array}$ & $\begin{array}{l}0.52 \\
0.36\end{array}$ & 0.0116 & $N S_{1}$ & NS \\
\hline \multirow[t]{2}{*}{ NEFA (mmol/l) } & Control & 0.62 & 0.14 & 0.63 & 0.16 & 0.64 & 0.11 & 0.63 & 0.13 & 0.61 & 0.15 & & & \\
\hline & HFHFR & $0.33^{\star \star \star}$ & 0.05 & 0.50 & 0.13 & $0.42^{\star \star}$ & 0.13 & $0.31^{\star \star \star}$ & 0.09 & $0.40^{*}$ & 0.13 & NS & $<0.0001$ & NS \\
\hline \multirow[t]{2}{*}{ ALAT (U/I) } & Control & $18 \cdot 4$ & 5.5 & 17.9 & 7.1 & 23.8 & 8.0 & $19 \cdot 1$ & 6.8 & $14 \cdot 8$ & 7.3 & & & \\
\hline & HFHFR & $23 \cdot 2$ & $7 \cdot 0$ & $30 \cdot 0^{\star}$ & $8 \cdot 2$ & 29.3 & 7.9 & $33 \cdot 6^{*}$ & $17 \cdot 2$ & $30 \cdot 1^{\star *}$ & 10.5 & NS & $<0.0001$ & NS \\
\hline
\end{tabular}

HFHFR, high-fat-high-fructose; HOMA-IR, homoeostasic model assessment of insulin resistance (mM glucose $\times \mathrm{mU} / \mathrm{linsulin}$ )/22.5; ALAT, alanine transaminase.

All the groups were tested for the effects of diet, treatment duration and their interaction by two-way ANOVA test. When the effects of diet, treatment duration or their interaction were significant, one-way ANOVA test was applied to analyse the effect of treatment duration for each diet followed up by a Fisher's least significant difference test, and the unpaired Student's $t$ test was used to analyse the effect of HFHFR diet within each treatment duration point.

The limit of statistical significance was set at $P<0.05$. HFHFR diet $v$. control diet: ${ }^{\star} P<0.05,{ }^{\star \star} P<0.005,{ }^{\star \star \star} P<0.0005$

a,b,c Inside the same diet, over treatment durations, mean values with unlike superscript letters are significantly different.

higher with the HFHFR diet, particularly the liver and adipose tissue weights (Table 1).

Plasma glucose was significantly increased throughout the study (with a maximal value at 12 weeks of diet) and was significantly higher with the HFHFR diet compared with the control diet (Table 2). Plasma insulin level was significantly increased throughout the study in both rat groups (Table 2). Moreover, when considering the 8- to 20-weeks experimental period, plasma insulin levels were significantly increased with the HFHFR diet compared with the control diet $(P<0.05)$. Consequently, HOMA-IR was also significantly increased throughout the study and was increased with the HFHFR diet compared with the control diet (Table 2). In agreement with these results, the OGTT showed that glucose intolerance was increased with the HFHFR diet compared with the control diet, which was maximal at 12 weeks of diet administration (Fig. 1).

Serum levels of both TAG and total CHOL were gradually and significantly increased throughout the study in both diet groups, whereas HFHFR diet had no significant effect on these both parameters (Table 2). On the other hand, serum NEFA level, as well as serum ALAT level, a marker of liver damage indicative of both cellular leakage and loss of liver cell membrane functional integrity, were significantly decreased and increased, respectively, with the HFHFR diet compared with the control diet (Table 2).

\section{Liver lipid content}

Total liver fat (TAG, CHOL esters, free $\mathrm{CHOL}$ and NEFA) gradually increased throughout the study under both diets and plateaued on 12 weeks of diet intake. As expected, total liver fat was largely more increased under the HFHFR diet, in particular on 12 weeks of diet intake (Table 3). Thus, the hepatic steatosis, defined when intrahepatic lipid content exceeds $5 \%$ of hepatic tissue $^{(23)}$, was maximal at 12 weeks of HFHFR diet with a slight amelioration afterwards. When regarded individually, the liver TAG and CHOL ester contents were highly increased (TAG were $2 \cdot 5$ times increased compared to control rats at 12 weeks of diet), whereas CHOL and NEFA were only moderately increased under the HFHFR diet.

\section{Mitochondrial biogenesis, mitochondrial characteristics and activity}

The liver PGC1-a protein expression, considered as the major mitochondrial biogenesis factor, tended to be modified with the HFHFR diet compared with the control diet $(P=0.09)$ with a highest expression at 12 weeks of HFHFR diet (Fig. 2). In addition, the gene expression of TFAM, PGC1-a-dependent gene and a regulator of mitochondrial biogenesis, decreased throughout the study, and this decrease was much more pronounced with the HFHFR diet compared with the control diet (Fig. 2). Finally, liver CS activity, commonly used as marker of mitochondrial content, was decreased throughout the study, but it remained similar with the control and HFHFR diets (Table 4).

Mitochondrial membrane potential and mitochondrial respiration and ROS production were differently altered throughout the study. Indeed, mitochondrial membrane potential remained stable throughout the study but was increased with the HFHFR diet compared with the control diet (Table 4). On the other hand, mitochondrial respiration and ROS production were decreased and increased, respectively, throughout the study but remained similar between both tested diets.

The enzymatic activity of liver mitochondrial complex I remained unchanged throughout the study but was decreased with the HFHFR diet compared with the control diet (Table 4). Complex II and complexes II+ III activities were altered throughout the study and were decreased with the HFHFR diet compared with the control diet. Complex IV (COX) activity was decreased throughout the study but remained unchanged with the HFHFR diet compared with the control diet. Finally, in the present study, mitochondrial $\beta$-HAD activity was increased throughout the study and largely increased with the HFHFR diet compared with the control diet (Table 4). 
(A)

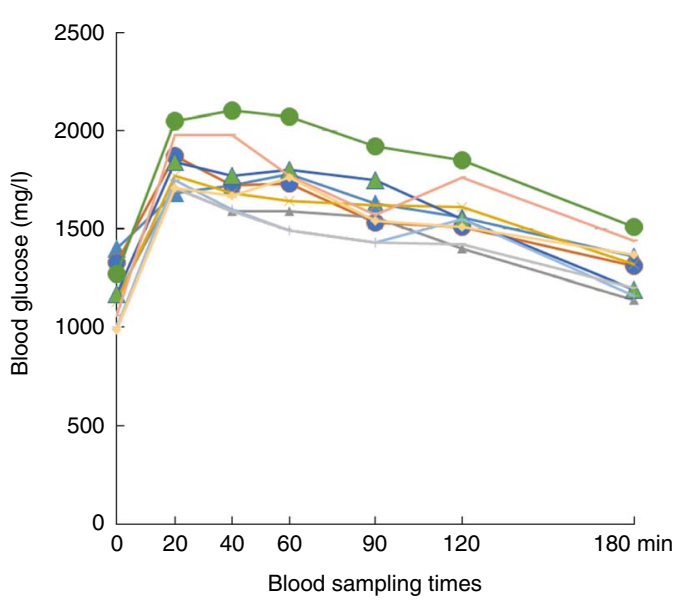

(B)

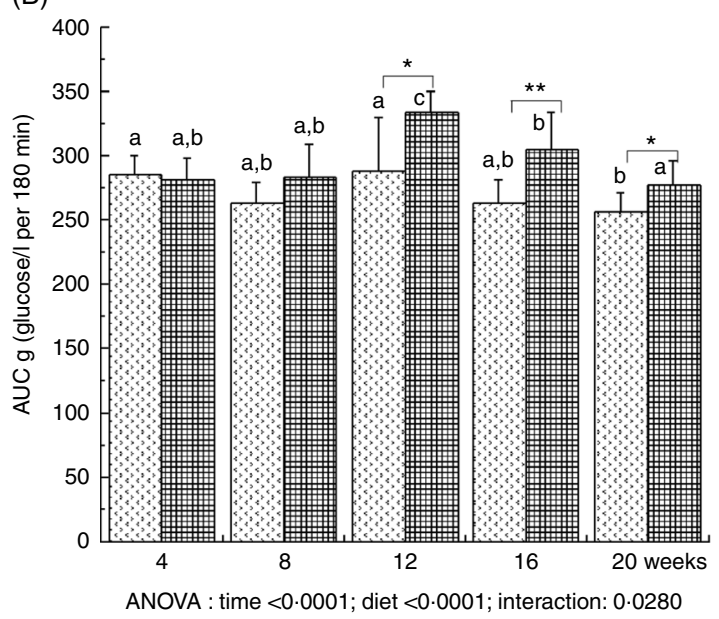

Fig. 1. Time-evolution of glucose intolerance in rats fed control (CTRL) or high-fat-high-fructose (HFHFR) diets for 4-20 weeks. A period of 6-h fasting rats received by oral administration $2.5 \mathrm{~g}$ glucose $/ \mathrm{kg}$ body weight. Blood was sampled through the tail vein of conscious rats immediately before the oral administration, and $20,40,60,90,120$ and $180 \mathrm{~min}$ afterwards and blood glucose was measured using glucose strips and a commercial glucometer (A). Total cumulative glucose levels for each treatment group are reported as AUC and were calculated by the trapezium method and expressed as g glucose/l per $180 \mathrm{~min}$ (B). Values are means ( $n 6-8$ animals/group per treatment duration), and standard deviations. All the groups were tested for the effects of diet, treatment duration and their interaction by two-way ANOVA test. When the effects of diet, treatment duration or their interaction were significant, one-way ANOVA test was applied to analyse the effect of treatment duration for each diet followed up by a Fisher's least significant. difference test, and the unpaired Student's $t$ test was used to analyse the effect of HFHFR diet within each treatment duration point. A: ——, 4 weeks/CTRL; $-1-, 4$ weeks/

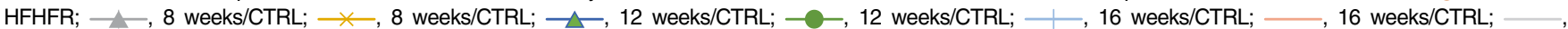

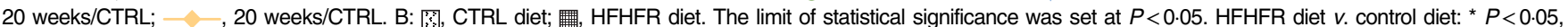
${ }^{* *} P<0.005$. ${ }^{\mathrm{a}, \mathrm{b}}$ Inside the same diet, over treatment durations, the mean values with unlike letters are significantly different.

Table 3. Abundance of neutral lipids in liver lipid extract

(Mean values and standard deviations; $n$ 6-8 animals/group per treatment duration)(Mean values and standard deviations; $n$ 6-8 animals/group per treatment duration)

\begin{tabular}{|c|c|c|c|c|c|c|c|c|c|c|c|c|c|c|}
\hline \multirow[b]{2}{*}{ Parameters } & \multirow[b]{2}{*}{ Diet } & \multicolumn{2}{|c|}{4 weeks } & \multicolumn{2}{|c|}{8 weeks } & \multicolumn{2}{|c|}{12 weeks } & \multicolumn{2}{|c|}{16 weeks } & \multicolumn{2}{|c|}{20 weeks } & \multirow[b]{2}{*}{ Time $(P)$} & \multirow[b]{2}{*}{ Diet $(P)$} & \multirow[b]{2}{*}{ Time $\times \operatorname{diet}(P)$} \\
\hline & & Mean & SD & Mean & SD & Mean & SD & Mean & SD & Mean & SD & & & \\
\hline \multirow{2}{*}{$\begin{array}{l}\text { Total liver fat } \\
\text { (mg/g wet wt) }\end{array}$} & Control & $23 \cdot 5^{a}$ & $4 \cdot 2$ & $21.9^{a}$ & $7 \cdot 6$ & $34 \cdot 1^{\mathrm{b}}$ & $6 \cdot 3$ & $30 \cdot 7^{\mathrm{b}}$ & $7 \cdot 7$ & $32 \cdot 3^{b}$ & $7 \cdot 8$ & & & \\
\hline & HFHFR & $49 \cdot 3^{* \star a}$ & $16 \cdot 7$ & $57 \cdot 3^{\star \star \star a}$ & 14.5 & $78 \cdot 2^{\star \star \star b}$ & 21.3 & $61 \cdot 4^{\star * a, b}$ & $20 \cdot 2$ & $47 \cdot 3^{\star a}$ & 11.4 & 0.0012 & $<0.0001$ & NS \\
\hline \multirow{2}{*}{$\begin{array}{l}\text { NEFA } \\
\text { (mg/g wet wt) }\end{array}$} & Control & $0.53^{a}$ & 0.08 & $0.73^{\mathrm{b}}$ & 0.18 & $0.84^{\mathrm{b}, \mathrm{c}}$ & 0.24 & $0.97^{c}$ & 0.23 & $1.00^{c}$ & 0.11 & & & \\
\hline & HFHFR & $0.58^{\mathrm{a}}$ & 0.14 & $0.63^{a, b}$ & 0.12 & $0.55^{\star a}$ & 0.11 & $0.75^{\star b}$ & 0.19 & $0.68^{\star \star \star a, b}$ & 0.14 & $<0.0001$ & $<0.0001$ & 0.0162 \\
\hline \multirow{2}{*}{$\begin{array}{l}\text { Free cholesterol } \\
(\mathrm{mg} / \mathrm{g} \text { wet } \mathrm{wt})\end{array}$} & Control & $1.66^{\mathrm{a}}$ & 0.23 & $1.58^{\mathrm{a}}$ & 0.16 & $2 \cdot 02^{b}$ & 0.26 & $1.69^{\mathrm{a}}$ & 0.19 & $1.67^{\mathrm{a}}$ & $0 \cdot 10$ & & & \\
\hline & HFHFR & $1.91^{\mathrm{a}}$ & 0.31 & $1.73^{\mathrm{a}, \mathrm{b}}$ & 0.11 & $1.87^{\mathrm{a}}$ & 0.19 & $1.67^{b}$ & 0.13 & $1.66^{\mathrm{b}}$ & 0.08 & 0.0003 & NS & NS \\
\hline \multirow{2}{*}{$\begin{array}{l}\text { Cholesteryl ester } \\
\text { (mg/g wet wt) }\end{array}$} & Control & $3 \cdot 3^{\mathrm{a}}$ & 1.0 & $3 \cdot 2^{a}$ & 1.4 & $6 \cdot 8^{\mathrm{b}}$ & 1.6 & $6 \cdot 8^{\mathrm{b}}$ & 1.0 & $5 \cdot 3^{\mathrm{c}}$ & $1 \cdot 2$ & & & \\
\hline & HFHFR & $8.9^{\star \star a}$ & 3.4 & $12 \cdot 0^{\star \star \star \star a}$ & 4.9 & $20 \cdot 1^{\star \star \star b}$ & $6 \cdot 6$ & $16 \cdot 9^{\star \star \star b, c}$ & 3.5 & $12 \cdot 1^{\star \star \star a, b}$ & $2 \cdot 4$ & $<0.0001$ & $<0.0001$ & 0.0284 \\
\hline \multirow[t]{2}{*}{ TAG (mg/g wet wt) } & Control & $17 \cdot 1^{a, b}$ & 4.6 & $14 \cdot 9^{\mathrm{a}}$ & $6 \cdot 6$ & $23 \cdot 0^{\mathrm{b}}$ & 4.6 & $19 \cdot 7^{\mathrm{a}, \mathrm{b}}$ & $6 \cdot 4$ & $21 \cdot 8^{b}$ & $6 \cdot 8$ & & & \\
\hline & HFHFR & $36 \cdot 8^{\star \star a}$ & $14 \cdot 3$ & $41 \cdot 4^{\star \star \star a}$ & 10.5 & $54 \cdot 5^{\star \star \star b}$ & $15 \cdot 2$ & $41 \cdot 0^{\star \star \star a}$ & $16 \cdot 6$ & $31 \cdot 7^{\star a}$ & 8.8 & 0.0177 & $<0.0001$ & NS \\
\hline
\end{tabular}

HFHFR, high-fat-high-fructose.

All the groups were tested for the effects of diet, treatment duration and their interaction by two-way ANOVA test. When the effects of diet, treatment duration or their interaction were significant, one-way ANOVA test was applied to analyse the effect of treatment duration for each diet followed up by a Fisher's least significant difference test, and the unpaired

Student's $t$ test was used to analyse the effect of HFHFR diet within each treatment duration point.

The limit of statistical significance was set at $P<0.05$. HFHFR diet $v$. control diet: ${ }^{\star} P<0.05,{ }^{\star \star} P<0.005,{ }^{\star \star \star} ~ P<0.0005$.

$\mathrm{a}, \mathrm{b}, \mathrm{c}$ Inside the same diet, over treatment durations, mean values with unlike superscript letters are significantly different.

\section{Mitochondrial phospholipid classes}

The total phospholipid content in the liver mitochondria was slightly decreased throughout the study without significant effect of the HFHFR diet compared with the control diet (Table 5). More specifically, the content of the major phospholipid, PC, was increased in liver mitochondria during the study similarly with both tested diets. The contents of the second major phospholipid, PE, and the PI were also decreased during the study with less impact with the HFHFR diet compared with the control diet. Consequently, the PC:PE ratio was increased throughout the study and decreased with the HFHFR diet compared with the control diet. Less expected is the large decrease in SM content throughout the study and slightly under the HFHFR diet. More interestingly, the mitochondrial CL content was increased throughout the study and under the HFHFR diet (Table 5). The CL content was maximal at 8-12 weeks, under both diets, the maximal value being $10 \%$ higher with HFHFR compared with control diet, whereas these increases were attenuated at 16 and 20 weeks with both diets. 
(A)

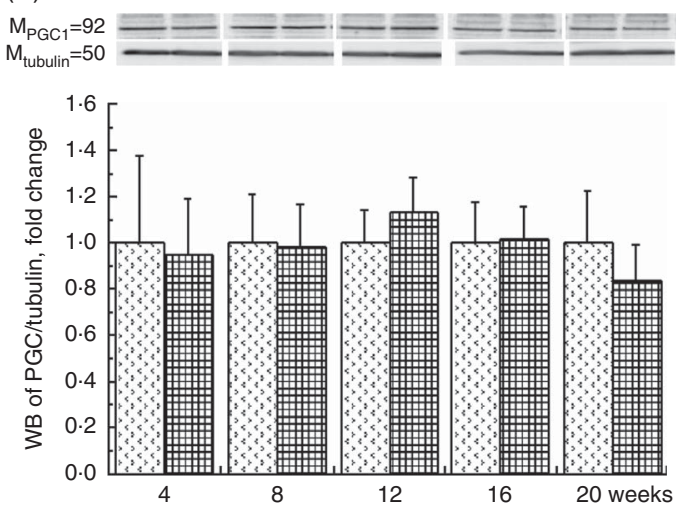

(B)

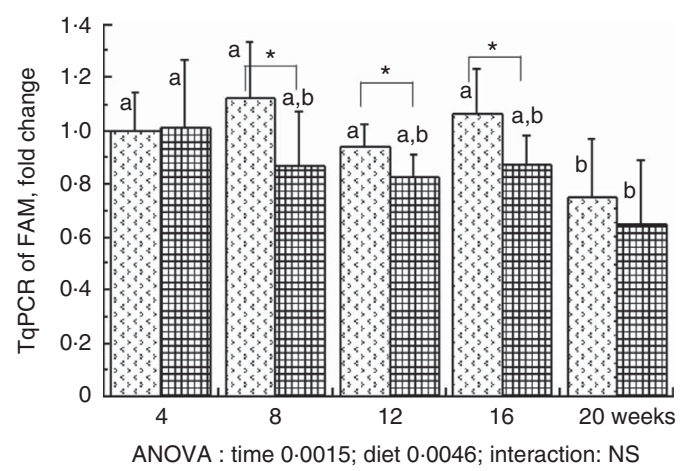

Fig. 2. Relative PPAR- $\gamma$ coactivator $1 a(P G C 1-a)$ protein expression (A) and relative mitochondrial transcription factor $A$ (Tfam) gene expression (B) in rats fed control (CTRL) or high-fat-high-fructose (HFHFR) diets for 4-20 weeks. Values are means ( $n$ 6-8 animals/group per treatment duration), and standard deviations. For PGC1-a protein expression, the statistical analysis was carried out time by time and thus comparison among time points was not possible. Comparison was then made only between control and HFHFR diets inside of each time point by the unpaired Student's $t$ test. For Tfam gene expression, the groups were tested for the effects of diet, treatment duration and their interaction by two-way ANOVA test. When the effects of diet, treatment duration or their interaction were significant, one-way ANOVA test was applied to analyse the effect of treatment duration for each diet followed up by a Fisher's least significant difference test, and

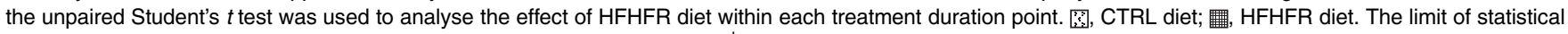
significance was set at $P<0.05$. HFHFR diet $v$. control diet: ${ }^{*} P<0.05 .{ }^{a, b}$ Inside the same diet, over treatment durations, the mean values with unlike letters are significantly different.

However, although CLS protein and gene expression remained stable throughout the study, both of them decreased with the HFHFR diet (Fig. 3).

\section{Fatty acid composition of liver mitochondrial phospholipids and desaturase indices}

Major fatty acid composition of liver mitochondrial phopholipids was altered throughout the study and especially with the HFHFR diet since the 4th week of diet (Table 6). Indeed, total SFA percentage was decreased throughout the study, because palmitic acid remained stable, whereas stearic acid was significantly decreased. As expected, total SFA percent was increased under the HFHFR diet, which was only owing to the increase in palmitic acid, whereas stearic acid remained unchanged. The percentage of the individual minor MUFA (C16:1n-9, C16:1n-7, C18:1n-7) was significantly increased, whereas the major MUFA, C18:1n-9, was only slightly increased throughout the study. Under the HFHFR diet, the percentage of total MUFA was largely increased, principally owing to the increase in the major MUFA, C18:1n-9 (+200\%), in spite of a decrease in the two other MUFA, C16:n-7 and C18: $1 n-7$ (Table 6, online Supplementary Fig. S1). Finally, the percentage of PUFA was decreased throughout the study (particularly C20 : n-6 and C22:6n-3) and under the HFHFR diet compared with the control diet, including all the five major PUFA. It is also noticeable that linoleic (18:2n-6), $\alpha$-linolenic $(18: 3 n-6)$ and dihomo- $\gamma$-linolenic $(20: 3 n-6)$ acids were minimal at 12 weeks of HFHFR diet, whereas the percentage of palmitoleic $(16: 1 n-7)$ and vaccenic $(18: 1 n$-7) acids was maximal at 12 weeks of HFHFR diet (Table 6).

The UI of mitochondrial phospholipids fatty acids was nonsignificantly decreased throughout the study and significantly decreased with the HFHFR diet compared with the control diet
(Table 6). This decreased UI was in agreement with the decrease in the percentage of PUFA throughout the study and under the HFHFR diet compared with the control diet. Regarding the fatty acid desaturase activities, the respective indices of the two desaturases $(\Delta 9=(16: 1 n-7 / 16: 0)$ and $\Delta 5)=(20: 4 n-6 / 20: 3 n-6)$ were altered throughout the study and were decreased markedly with the HFHFR diet compared with the control diet, whereas the $\Delta 6$ desaturase index (18: $3 n-6 / 18: 2 n-6)$ only tended to be modified with the HFHFR diet (Table 6). This is in agreement with the above reported decreases in the percent of PUFA and in the UI.

\section{Discussion}

Hyperlipidic-hyperenergetic diets are now frequently consumed in modern societies, coupled with low levels of physical activity. These factors contribute importantly to the development of pathological conditions, which include obesity, dyslipidaemia, NAFLD, IR and diabetes. The exact sequence of events leading to metabolic alterations and NAFLD installation and progression, in particular mitochondrial structure alteration and dysfunction and their interrelation, still remains to be characterised. This study aimed to explore the time-evolution of liver mitochondrial structure and function changes associated with hepatic steatosis installation and progression in rats fed an obesogenic diet for 4-20 weeks. These time intervals are interesting because they cover short-term ( 4 weeks), usual-term (12 weeks) and long-term (20 weeks) dietary interventions. In this study, the HFHFR diet tested, rich in fat and fructose, has been shown to be efficient in inducing moderate overweight, increased liver and adipose tissue weights, hyperglycaemia and hyperinsulinaemia since the 8 th week of diet. The hepatic enlargement reflected an overt hepatic steatosis, objectivised principally by an increased level of liver TAG and CHOL ester 
Table 4. Mitochondrial activity and mitochondrial membrane fluidity in liver

(Mean values and standard deviations; $n$ 6-8 animals/group per treatment duration)

\begin{tabular}{|c|c|c|c|c|c|c|c|c|c|c|c|c|c|c|}
\hline \multirow[b]{2}{*}{ Parameters } & \multirow[b]{2}{*}{ Diet } & \multicolumn{2}{|c|}{4 weeks } & \multicolumn{2}{|c|}{8 weeks } & \multicolumn{2}{|c|}{12 weeks } & \multicolumn{2}{|c|}{16 weeks } & \multicolumn{2}{|c|}{20 weeks } & \multirow[b]{2}{*}{ Time $(P)$} & \multirow[b]{2}{*}{ Diet $(P)$} & \multirow{2}{*}{$\begin{array}{c}\text { Time } \times \text { diet } \\
(P)\end{array}$} \\
\hline & & Mean & SD & Mean & SD & Mean & SD & Mean & SD & Mean & SD & & & \\
\hline \multirow[t]{2}{*}{ Mitochondrial membrane potential (AU) } & Control & $55 \cdot 5^{\mathrm{a}}$ & 6.4 & $54.0^{\mathrm{a}}$ & $9 \cdot 2$ & $57 \cdot 1^{\mathrm{a}}$ & 4.8 & $51 \cdot 2^{a, b}$ & $6 \cdot 3$ & $47 \cdot 8^{\mathrm{b}}$ & 3.7 & & & \\
\hline & HFHFR & $57 \cdot 8^{\mathrm{a}, \mathrm{b}}$ & $4 \cdot 1$ & $56 \cdot 2^{\mathrm{a}, \mathrm{b}}$ & 3.6 & $59 \cdot 7^{\mathrm{a}}$ & 4.4 & $53 \cdot 6^{\mathrm{b}}$ & 7.3 & $48 \cdot 3^{\mathrm{c}}$ & $4 \cdot 1$ & $<0.0001$ & 0.0598 & NS \\
\hline \multirow[t]{2}{*}{ Mitochondrial ROS production (AU) } & Control & $128^{\mathrm{a}}$ & 24 & $161^{\mathrm{b}}$ & 27 & $160^{\mathrm{b}}$ & 30 & $173^{b}$ & 29 & $260^{c}$ & 33 & & & \\
\hline & HFHFR & $130^{\mathrm{a}}$ & 9 & $155^{\mathrm{a}, \mathrm{b}}$ & 25 & $148^{\mathrm{a}, \mathrm{b}}$ & 46 & $177^{\mathrm{b}}$ & 30 & $260^{c}$ & 31 & $<0.0001$ & NS & NS \\
\hline \multirow[t]{2}{*}{ Mitochondrial respiration ( $\mathrm{nmol} \mathrm{O}_{2} / \mathrm{s}$ per $\mathrm{mg}$ protein) } & Control & $1.25^{\mathrm{a}}$ & 0.31 & $0.97^{\mathrm{a}}$ & 0.27 & $1.22^{\mathrm{a}}$ & 0.40 & $1.19^{\mathrm{a}}$ & 0.42 & $0.96^{\mathrm{a}}$ & 0.32 & & & \\
\hline & HFHFR & $1.25^{\mathrm{a}}$ & 0.28 & $0.96^{\mathrm{a}, \mathrm{b}}$ & 0.27 & $0.93^{b}$ & 0.23 & $1 \cdot 13^{\mathrm{a}, \mathrm{b}}$ & 0.33 & $0.83^{b}$ & 0.49 & 0.0199 & NS & NS \\
\hline \multirow[t]{2}{*}{ Citrate synthase activity (mU/g liver wet wt) } & Control & $16 \cdot 2^{\mathrm{a}}$ & 2.3 & $15 \cdot 3^{\mathrm{a}}$ & 2.0 & $15 \cdot 5^{\mathrm{a}}$ & 1.7 & $13 \cdot 3^{\mathrm{b}}$ & 1.2 & $12 \cdot 9^{\mathrm{b}}$ & 1.9 & & & \\
\hline & HFHFR & $15 \cdot 4^{a}$ & 0.7 & $15 \cdot 8^{a}$ & $2 \cdot 1$ & $14 \cdot 4^{\mathrm{a}, \mathrm{b}}$ & 0.9 & $13 \cdot 7^{\mathrm{b}}$ & $2 \cdot 1$ & $14 \cdot 0^{\mathrm{b}}$ & 1.0 & $<0.0001$ & NS & NS \\
\hline \multirow[t]{2}{*}{ Complex I activity (mU/mg protein) } & Control & 123 & 25 & 133 & 26 & 162 & 38 & 136 & 26 & 125 & 24 & & & \\
\hline & HFHFR & 116 & 25 & 108 & 43 & $122^{*}$ & 26 & 115 & 20 & 123 & 46 & NS & 0.0065 & NS \\
\hline \multirow[t]{2}{*}{ Complex II activity (mU/mg protein) } & Control & $301^{\mathrm{a}}$ & 61 & $382^{\mathrm{b}}$ & 46 & $423^{b, c}$ & 40 & $434^{c}$ & 52 & $389^{\mathrm{b}, \mathrm{c}}$ & 39 & & & \\
\hline & HFHFR & $300^{\mathrm{a}}$ & 64 & $374^{\mathrm{b}}$ & 49 & $386^{* b}$ & 28 & $384^{* \mathrm{~b}}$ & 35 & $333^{\star a, b}$ & 59 & $<0.0001$ & 0.0085 & NS \\
\hline \multirow[t]{2}{*}{ Complexes II + III activity (mU/mg protein) } & Control & $166^{\mathrm{a}}$ & 80 & $347^{\mathrm{b}}$ & 75 & $343^{b}$ & 73 & $494^{\mathrm{C}}$ & 78 & $246^{\mathrm{d}}$ & 53 & & & \\
\hline & HFHFR & $79^{\star a}$ & 81 & $180^{\star b}$ & 32 & $250^{* c}$ & 52 & $323^{\star \star \star d}$ & 62 & $153^{\star b}$ & 71 & $<0.0001$ & $<0.0001$ & NS \\
\hline \multirow[t]{2}{*}{ Complex IV activity (U/mg protein) } & Control & $1.43^{\mathrm{a}}$ & 0.15 & $1.42^{\mathrm{a}}$ & 0.26 & $1.40^{\mathrm{a}}$ & 0.11 & $1.39^{a}$ & 0.12 & $1.23^{\mathrm{b}}$ & 0.11 & & & \\
\hline & HFHFR & $1.45^{\mathrm{a}}$ & 0.09 & $1.41^{\mathrm{a}}$ & 0.19 & $1.32^{\mathrm{a}}$ & 0.11 & $1.38^{\mathrm{a}}$ & 0.14 & $1.13^{\mathrm{b}}$ & 0.23 & 0.0002 & NS & NS \\
\hline \multirow[t]{2}{*}{$\beta$-HAD activity (mU/mg protein) } & Control & $222^{a}$ & 80 & $302^{a, b}$ & 100 & $355^{\mathrm{b}}$ & 76 & $255^{\mathrm{a}}$ & 77 & $282^{a, b}$ & 72 & & & \\
\hline & HFHFR & $550^{\star \star \star a}$ & 85 & $623^{\star \star \star b, c}$ & 58 & $639^{\star \star \star b, c}$ & 75 & $570^{\star \star * a, b}$ & 80 & $670^{\star \star \star \star c}$ & 64 & 0.0008 & $<0.0001$ & NS \\
\hline
\end{tabular}

$\mathrm{AU}$, arbitrary units; HFHFR, high-fat-high-fructose; ROS, reactive oxygen species; $\beta$-HAD, $\beta$-hydroxyacyl-CoA dehydrogenase.

All the groups were tested for the effects of diet, treatment duration and their interaction by two-way ANOVA test. When the effects of diet, treatment duration or their interaction were significant, one-way ANOVA test was applied to analyse the effect of treatment duration for each diet followed up by a Fisher's least significant difference test, and the unpaired Student's $t$ test was used to analyse the effect of HFHFR diet within each treatment duration point. Membrane potential expressed as fluorescence of rhodamine 123 in the presence of substrates (malate/glutamate/succinate) and ADP. Mitochondrial ROS production expressed as fluorescence of $2^{\prime}, 7^{\prime}$-dichlorofluorescein diacetate in the presence of substrates (malate/glutamate/succinate) and ADP. Mitochondrial respiration was measured in the presence of substrates (malate/glutamate/succinate) and ADP.

The limit of statistical significance was set at $P<0.05$. HFHFR diet $V$. control diet: ${ }^{*} P<0.05$, ${ }^{* *} P<0.005$, ${ }^{* * *} P<0.0005$.

a,b,c,d Inside the same diet, over treatment durations, mean values with unlike superscript letters are significantly different. 
Table 5. Abundance of phospholipid classes in liver mitochondrial lipid extract (Mean values and standard deviations; $n$ 6-8 animals/group per treatment duration)

\begin{tabular}{|c|c|c|c|c|c|c|c|c|c|c|c|c|c|c|}
\hline \multirow[b]{2}{*}{ Parameters } & \multirow[b]{2}{*}{ Diet } & \multicolumn{2}{|c|}{4 weeks } & \multicolumn{2}{|c|}{8 weeks } & \multicolumn{2}{|c|}{12 weeks } & \multicolumn{2}{|c|}{16 weeks } & \multicolumn{2}{|c|}{20 weeks } & \multirow{2}{*}{$\begin{array}{c}\text { Time } \\
(P)\end{array}$} & \multirow[b]{2}{*}{$\operatorname{Diet}(P)$} & \multirow{2}{*}{$\begin{array}{c}\text { Time } \times \text { diet } \\
(P)\end{array}$} \\
\hline & & Mean & SD & Mean & SD & Mean & SD & Mean & SD & Mean & SD & & & \\
\hline \multirow{2}{*}{$\begin{array}{l}\text { Phospholipids } \\
\text { (nmol/mg } \\
\text { protein) }\end{array}$} & Control & $317^{a}$ & 21 & $316^{a}$ & 38 & $308^{a, b}$ & 46 & $273^{b}$ & 28 & $292^{a, b}$ & 31 & & & \\
\hline & HFHFR & $345^{a}$ & 50 & $342^{a}$ & 50 & $306^{a, b}$ & 15 & $288^{\mathrm{b}}$ & 28 & $288^{b}$ & 32 & 0.0002 & NS & NS \\
\hline \multirow{2}{*}{$\begin{array}{l}\mathrm{PC}(\mathrm{nmol} / \mathrm{mg} \\
\text { protein) }\end{array}$} & Control & $150^{\mathrm{a}}$ & 11 & $152^{\mathrm{a}}$ & 19 & $150^{\mathrm{a}}$ & 23 & $135^{\mathrm{a}}$ & 14 & $149^{a}$ & 16 & & & \\
\hline & HFHFR & $163^{a}$ & 24 & $158^{\mathrm{a}}$ & 24 & $142^{\mathrm{a}, \mathrm{b}}$ & 9 & $137^{\mathrm{b}}$ & 15 & $145^{\mathrm{a}, \mathrm{b}}$ & 15 & 0.0251 & NS & NS \\
\hline \multirow{2}{*}{$\begin{array}{l}\mathrm{PE}(\mathrm{nmol} / \mathrm{mg} \\
\text { protein) }\end{array}$} & Control & $96 \cdot 0^{\mathrm{a}}$ & $6 \cdot 7$ & $94 \cdot 6^{\mathrm{a}}$ & 11.9 & $91 \cdot 1^{\mathrm{a}}$ & 13.8 & $79 \cdot 7^{\mathrm{b}}$ & 8.2 & $85 \cdot 2^{a, b}$ & $10 \cdot 0$ & & & \\
\hline & HFHFR & $106 \cdot 8^{a}$ & $15 \cdot 9$ & $105 \cdot 4^{\mathrm{a}}$ & $14 \cdot 8$ & $90 \cdot 2^{\mathrm{b}}$ & 1.8 & $89 \cdot 0^{* \mathrm{~b}}$ & 8.9 & $85 \cdot 4^{\mathrm{b}}$ & 10.8 & $<0.0001$ & 0.0155 & NS \\
\hline \multirow[t]{2}{*}{$\mathrm{PC} / \mathrm{PE}$ ratio } & Control & $1.56^{\mathrm{a}}$ & 0.06 & $1 \cdot 61^{a, b}$ & 0.06 & $1.65^{a, b}$ & 0.08 & $1 \cdot 70^{\mathrm{b}, \mathrm{c}}$ & 0.11 & $1.75^{\mathrm{c}}$ & 0.13 & & & \\
\hline & HFHFR & $1.51^{\mathrm{a}, \mathrm{b}}$ & 0.05 & $1.50^{* a}$ & 0.08 & $1.58^{\mathrm{b}}$ & $0 \cdot 10$ & $1.54^{\star \star a, b}$ & 0.04 & $1 \cdot 70^{\mathrm{C}}$ & 0.06 & $<0.0001$ & $<0.0001$ & NS \\
\hline \multirow{2}{*}{$\begin{array}{l}\mathrm{PI}(\mathrm{nmol} / \mathrm{mg} \\
\text { protein) }\end{array}$} & Control & $27 \cdot 6^{\mathrm{a}}$ & 1.3 & $25 \cdot 3^{\mathrm{a}, \mathrm{b}}$ & $2 \cdot 4$ & $23 \cdot 9^{\mathrm{b}}$ & 3.8 & $19 \cdot 5^{\mathrm{c}}$ & $2 \cdot 2$ & $20 \cdot 1^{\mathrm{c}}$ & $2 \cdot 1$ & & & \\
\hline & HFHFR & $30 \cdot 5^{\mathrm{a}}$ & $5 \cdot 8$ & $30 \cdot 7^{\star a}$ & $4 \cdot 3$ & $25 \cdot 0^{\mathrm{b}}$ & 1.7 & $23 \cdot 4^{\star b}$ & $3 \cdot 2$ & $23 \cdot 3^{\star b}$ & $3 \cdot 3$ & $<0.0001$ & $<0.0001$ & NS \\
\hline \multirow{2}{*}{$\begin{array}{l}\mathrm{SM}(\mathrm{nmol} / \mathrm{mg} \\
\text { protein) }\end{array}$} & Control & $11.06^{\mathrm{a}}$ & 1.48 & $9 \cdot 30^{\mathrm{b}}$ & 1.95 & $8.86^{\mathrm{b}}$ & 1.43 & $8.39^{\mathrm{b}, \mathrm{c}}$ & 1.31 & $7 \cdot 16^{c}$ & 1.48 & & & \\
\hline & HFHFR & $11 \cdot 26^{a}$ & 1.45 & $9.48^{\mathrm{b}}$ & $2 \cdot 17$ & $8.57^{\mathrm{b}, \mathrm{c}}$ & 0.46 & $7 \cdot 73^{\mathrm{c}}$ & 1.34 & $6 \cdot 88^{\mathrm{c}}$ & 2.00 & $<0.0001$ & NS & NS \\
\hline \multirow{2}{*}{$\begin{array}{l}\mathrm{PS}(\mathrm{nmol} / \mathrm{mg} \\
\text { protein) }\end{array}$} & Control & $9.63^{\mathrm{a}}$ & 0.93 & $8 \cdot 16^{\mathrm{b}}$ & 0.92 & $6 \cdot 81^{\mathrm{b}}$ & 1.50 & $7.02^{\mathrm{b}}$ & 1.65 & $7 \cdot 62^{\mathrm{b}}$ & 1.23 & & & \\
\hline & HFHFR & $10 \cdot 36^{a}$ & 1.82 & $8 \cdot 80^{a, b}$ & 2.66 & $\begin{array}{c}6.40^{\mathrm{c}} \\
26.9^{\mathrm{a}}\end{array}$ & 0.37 & $7 \cdot 71^{\mathrm{b}, \mathrm{c}}$ & 1.01 & $8.05^{\mathrm{b}, \mathrm{c}}$ & 1.40 & $<0.0001$ & NS & NS \\
\hline $\begin{array}{c}\mathrm{CL} \mathrm{nmol} / \mathrm{mg} \\
\text { protein }\end{array}$ & $\begin{array}{l}\text { Control } \\
\text { HFHFR }\end{array}$ & $\begin{array}{l}23 \cdot 5^{\mathrm{a}} \\
24 \cdot 8^{\mathrm{a}, \mathrm{b}}\end{array}$ & $\begin{array}{l}2 \cdot 4 \\
4.5\end{array}$ & $\begin{array}{l}26 \cdot 8^{\mathrm{a}} \\
29 \cdot 7^{\mathrm{d}}\end{array}$ & $\begin{array}{l}3 \cdot 6 \\
3.9\end{array}$ & $\begin{array}{l}26 \cdot 9^{\mathrm{a}} \\
28 \cdot 8^{\mathrm{c}, \mathrm{d}}\end{array}$ & $\begin{array}{l}4 \cdot 2 \\
2 \cdot 4\end{array}$ & $\begin{array}{l}23 \cdot 4^{\mathrm{a}} \\
26 \cdot 2^{* \mathrm{~b}, \mathrm{c}}\end{array}$ & $\begin{array}{l}3 \cdot 1 \\
2 \cdot 4\end{array}$ & $\begin{array}{l}23 \cdot 5^{\mathrm{a}} \\
22 \cdot 0^{\mathrm{a}}\end{array}$ & $\begin{array}{l}3 \cdot 4 \\
3.0\end{array}$ & $<0.001$ & 0.0318 & NS \\
\hline
\end{tabular}

HFHFR, high-fat-high-fructose; PC, phosphatidylcholine; PE, phosphatidylethanolamine; PI, phosphatidylinositol; SM, sphyngomyelin; PS, phosphatidylserine; CL, cardiolipin. All the groups were tested for the effects of diet, treatment duration and their interaction by two-way ANOVA test. When the effects of diet, treatment duration or their interaction were significant, one-way ANOVA test was applied to analyse the effect of treatment duration for each diet followed up by a Fisher's least significant difference test, and the unpaired Student's $t$ test was used to analyse the effect of HFHFR diet within each treatment duration point.

The limit of statistical significance was set at $P<0.05$. HFHFR diet $v$. control diet: ${ }^{*} P<0.05,{ }^{\star *} P<0.005,{ }^{\star * *} P<0.0005$

$\mathrm{a}, \mathrm{b}, \mathrm{c}, \mathrm{d}$ Inside the same diet, over treatment durations, mean values with unlike superscript letters are significantly different.

(A)

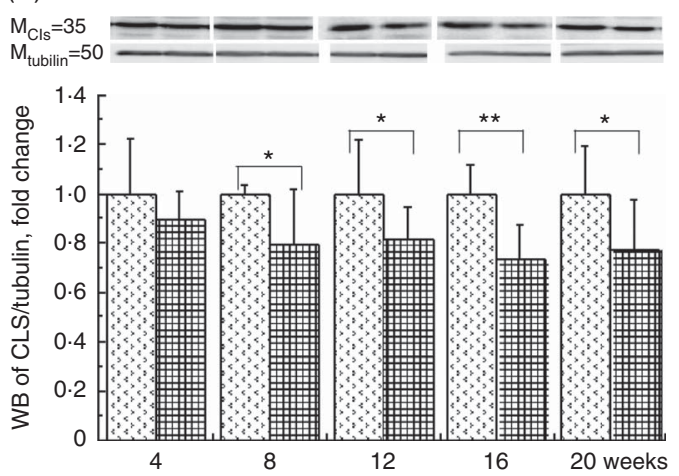

(B)

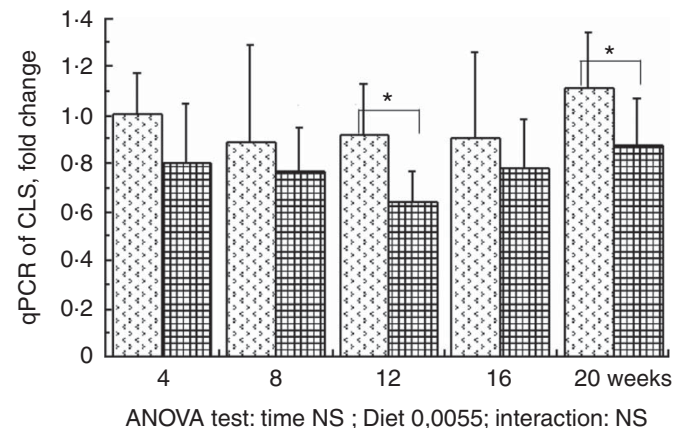

Fig. 3. Relative protein (A) and gene (B) expression of cardiolipin synthase (CLS) in rats fed control (CTRI) or high-fat-high-fructose (HFHFR) diets for 4-20 weeks. Values are means ( $n$ 6-8 animals/group per treatment duration), and standard deviations. For CLS protein expression, the analysis was carried out time by time and thus comparison among time points was not possible. Comparison was then made only between control and HFHFR diets inside of each time point by the unpaired Student's $t$ test. For gene expression, the groups were tested for the effects of diet, treatment duration and their interaction by two-way ANOVA test. When the effects of diet, treatment duration or their interaction were significant, one-way ANOVA test was applied to analyse the effect of treatment duration for each diet followed up by a Fisher's least significant difference test, and the unpaired Student's $t$ test was used to analyse the effect of HFHFR diet within each treatment duration point.

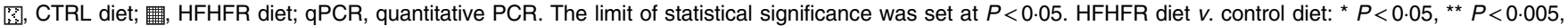
${ }^{\star * \star} P<0.0005$.

and plasma ALAT activity. In addition, the mitochondrial phospholipids PC/PE ratio was decreased with the obesogenic diet, which has been previously linked to NAFLD ${ }^{(24)}$.

In the present study, we have investigated five time points up to 20 weeks and we have carried out a control group and a HFHFR group at each studied time point. Indeed, rare are the dietary studies that lasted as long as 20 weeks. In a rat study as long as ours, Bai et al. ${ }^{(26)}$ showed that rat hepatic steatosis was established since the 8th weeks and remained stable until the end of their study at 20 weeks. However, Ferramosca et al. ${ }^{(25)}$ showed that hepatic steatosis installation (TAG and CHOL contents) in rat started since the 4th weeks and was increased gradually in their study points at 6, 8 and 12 weeks. In contrast, Gauthier et al. ${ }^{(5)}$ have observed in female rats that liver lipid content was increased rapidly (+200\%) during the first 2 weeks but was decreased between 2 and 6 weeks and was re-increased slightly between 6 and 16 weeks. Finally, in a mice study, Satapati et $a l .{ }^{(27)}$ reported that hepatic steatosis was established since the 8th weeks and was increased in their study points at 16 and 32 weeks. It is possible that the observed differences in the installation and progression of hepatic steatosis 
Table 6. Fatty acid composition (\%) of liver mitochondrial lipids

(Mean values and standard deviations; $n$ 6-8 animals/group per treatment duration)

\begin{tabular}{|c|c|c|c|c|c|c|c|c|c|c|c|c|c|c|}
\hline \multirow[b]{2}{*}{ Parameters } & \multirow[b]{2}{*}{ Diet } & \multicolumn{2}{|c|}{4 weeks } & \multicolumn{2}{|c|}{8 weeks } & \multicolumn{2}{|c|}{12 weeks } & \multicolumn{2}{|c|}{16 weeks } & \multicolumn{2}{|c|}{20 weeks } & \multirow[b]{2}{*}{ Time $(P)$} & \multirow[b]{2}{*}{$\operatorname{Diet}(P)$} & \multirow[b]{2}{*}{ Time $\times$ diet $(P)$} \\
\hline & & Mean & SD & Mean & SD & Mean & SD & Mean & SD & Mean & SD & & & \\
\hline \multirow[t]{2}{*}{ Total SFA } & Control & $36.0^{\mathrm{a}}$ & $0 \cdot 8$ & $35 \cdot 3^{\mathrm{a}}$ & 1.9 & $34 \cdot 2^{\mathrm{a}, \mathrm{b}}$ & 2.5 & $33.6^{\mathrm{b}}$ & 1.9 & $32 \cdot 7^{\mathrm{b}}$ & 1.8 & & & \\
\hline & HFHFR & $37 \cdot 2^{\mathrm{a}}$ & 2.5 & $35 \cdot 8^{a, b}$ & 1.7 & $35 \cdot 2^{a, b}$ & $2 \cdot 2$ & $34.9^{\mathrm{b}}$ & 1.2 & $36 \cdot 0^{* a, b}$ & 2.5 & 0.0064 & 0.0022 & NS \\
\hline \multirow[t]{2}{*}{ C14:0 } & Control & $0.60^{\mathrm{a}}$ & 0.12 & $0.70^{\mathrm{a}, \mathrm{b}}$ & 0.23 & $0.71^{a, b}$ & 0.20 & $0.71^{a, b}$ & 0.21 & $0.85^{b}$ & 0.23 & & & \\
\hline & HFHFR & $0.41^{\star a}$ & 0.09 & $0.52^{\star \mathrm{b}}$ & 0.06 & $0.52^{\star \mathrm{b}}$ & 0.14 & $0.49^{\star a, b}$ & 0.05 & $0.51^{\star \star b}$ & 0.07 & 0.0570 & $<0.0001$ & NS \\
\hline \multirow[t]{2}{*}{$\mathrm{C} 16: 0$} & Control & $22 \cdot 0$ & $1 \cdot 0$ & $23 \cdot 0$ & 1.4 & $22 \cdot 3$ & 0.9 & $22 \cdot 2$ & 0.6 & $23 \cdot 0$ & $1 \cdot 3$ & & & \\
\hline & HFHFR & $23 \cdot 8^{*}$ & 1.5 & $24 \cdot 3$ & 1.7 & $24 \cdot 9^{\star \star}$ & 1.7 & $24 \cdot 5^{\star \star \star}$ & 1.0 & $25 \cdot 1^{*}$ & 1.5 & NS & $<0.0001$ & NS \\
\hline \multirow[t]{2}{*}{ C18:0 } & Control & $12 \cdot 7^{\mathrm{a}}$ & 1.3 & $11 \cdot 1^{\mathrm{a}, \mathrm{b}}$ & $2 \cdot 2$ & $10 \cdot 6^{\mathrm{b}}$ & 2.5 & $10 \cdot 1^{\mathrm{b}, \mathrm{c}}$ & $2 \cdot 2$ & $8.35^{\mathrm{c}}$ & 1.89 & & & \\
\hline & HFHFR & $12 \cdot 4^{\mathrm{a}}$ & 3.7 & $10 \cdot 6^{\mathrm{a}}$ & 3.0 & $9.43^{\mathrm{a}}$ & 3.64 & $9.46^{\mathrm{a}}$ & 1.93 & $9.99^{\mathrm{a}}$ & 3.1 & 0.0109 & NS & NS \\
\hline \multirow{2}{*}{ Total MUFA } & Control & $21 \cdot 4^{\mathrm{a}}$ & 3.4 & $23 \cdot 5^{\mathrm{a}}$ & $4 \cdot 2$ & $24 \cdot 6^{\mathrm{a}, \mathrm{b}}$ & $5 \cdot 4$ & $24 \cdot 4^{a, b}$ & 5.0 & $28 \cdot 5^{\mathrm{b}}$ & $3 \cdot 1$ & & & \\
\hline & HFHFR & $33 \cdot 8^{\star * a}$ & $8 \cdot 1$ & $37 \cdot 2^{\star \star \star a}$ & $5 \cdot 7$ & $39 \cdot 9^{* \star a}$ & $7 \cdot 7$ & $39 \cdot 9^{\star \star \star a}$ & 3.7 & $38 \cdot 8^{\star \star a}$ & $7 \cdot 0$ & 0.0479 & $<0.0001$ & NS \\
\hline \multirow[t]{2}{*}{ C16:1n-9 } & Control & $0.23^{\mathrm{a}}$ & 0.04 & $0.27^{\mathrm{a}}$ & 0.06 & $0.36^{b}$ & 0.07 & $0.36^{\mathrm{b}}$ & 0.08 & $0.45^{\mathrm{c}}$ & 0.06 & & & \\
\hline & HFHFR & $0.25^{\mathrm{a}}$ & 0.05 & $0.34^{\mathrm{b}}$ & 0.08 & $0.40^{\mathrm{b}}$ & 0.10 & $0.36^{\mathrm{b}}$ & 0.05 & $0.41^{\mathrm{b}}$ & 0.05 & $<0.0001$ & NS & NS \\
\hline \multirow[t]{2}{*}{ C16:1n-7 } & Control & $3 \cdot 31^{\mathrm{a}}$ & 1.04 & $3 \cdot 91^{\mathrm{a}}$ & 1.33 & $4.48^{\mathrm{a}}$ & 1.82 & $4.68^{a}$ & 1.70 & $4.86^{a}$ & 1.38 & & & \\
\hline & HFHFR & $0.70^{\star \star \star a}$ & 0.23 & $1.09^{\star \star \star a, b}$ & 0.30 & $1.76^{\star \star d}$ & 0.77 & $1 \cdot 40^{\star \star \star b, c}$ & 0.36 & $1.64^{\star \star \star c, d}$ & 0.45 & 0.0179 & $<0.0001$ & NS \\
\hline \multirow[t]{2}{*}{ C18: $1 n-9$} & Control & $13 \cdot 2$ & 2.5 & $13 \cdot 8$ & $2 \cdot 8$ & 13.7 & $3 \cdot 1$ & 13.3 & 2.9 & $17 \cdot 8$ & $2 \cdot 3$ & & & \\
\hline & HFHFR & $30 \cdot 5^{\star \star \star}$ & 7.9 & $33 \cdot 5^{\star \star \star}$ & 5.4 & $35 \cdot 4^{\star * *}$ & $7 \cdot 3$ & $36 \cdot 0^{* \star *}$ & 3.7 & $35 \cdot 0^{\star \star *}$ & $6 \cdot 6$ & NS & $<0.0001$ & NS \\
\hline \multirow[t]{2}{*}{ C18: $1 n-7$} & Control & $4 \cdot 11^{\mathrm{a}}$ & 0.33 & $4.92^{b}$ & 0.55 & $5 \cdot 43^{\mathrm{c}}$ & 0.70 & $5 \cdot 63^{c}$ & 0.63 & $4.90^{b}$ & 0.38 & & & \\
\hline & HFHFR & $1.49^{* \star \star a, b}$ & 0.10 & $1.73^{\star \star \star b}$ & 0.22 & $1.82^{\star \star \star b}$ & 0.42 & $1.64^{\star \star * b}$ & 0.22 & $1 \cdot 19^{\star \star \star a}$ & 0.77 & $<0.0001$ & $<0.0001$ & 0.0028 \\
\hline \multirow[t]{2}{*}{ Total PUFA } & Control & 42.5 & $3 \cdot 2$ & $41 \cdot 1$ & $3 \cdot 4$ & $41 \cdot 0$ & 3.7 & 41.9 & 3.7 & $38 \cdot 7$ & $3 \cdot 3$ & & & \\
\hline & HFHFR & $27 \cdot 8^{\star \star \star}$ & 6.0 & $26 \cdot 9^{\star \star \star}$ & $4 \cdot 1$ & $24 \cdot 9^{\star \star \star}$ & 5.7 & $25 \cdot 2^{\star \star \star}$ & $2 \cdot 6$ & $25 \cdot 1^{\star \star \star}$ & 4.8 & NS & $<0.0001$ & NS \\
\hline \multirow{2}{*}{ C18:2n-6 } & Control & 19.5 & 1.7 & $19 \cdot 4$ & $2 \cdot 0$ & $18 \cdot 7$ & 2.5 & $20 \cdot 4$ & 1.8 & 20.5 & 3.1 & & & \\
\hline & HFHFR & $13 \cdot 1^{\star \star \star}$ & $0 \cdot 8$ & $13 \cdot 1^{\star \star \star}$ & 0.9 & $12 \cdot 4^{\star \star \star}$ & 1.3 & $13 \cdot 4^{\star \star \star}$ & 0.7 & $12 \cdot 8^{\star \star \star}$ & 0.9 & NS & $<0.0001$ & NS \\
\hline C18:3n-6 & Control & $0.25^{\mathrm{a}}$ & 0.06 & $0.32^{b, c}$ & 0.04 & $0.31^{\mathrm{b}, \mathrm{c}}$ & 0.06 & $0.30^{\mathrm{a}, \mathrm{b}}$ & 0.06 & $0.36^{\mathrm{c}}$ & 0.05 & & & \\
\hline & HFHFR & $0.27^{\mathrm{a}}$ & 0.08 & $0.23^{\star * a, b}$ & 0.04 & $0 \cdot 19^{* * b}$ & 0.04 & $0.21^{* * b}$ & 0.05 & $0 \cdot 22^{\star \star \star a, b}$ & 0.04 & NS & $<0.0001$ & 0.0016 \\
\hline C18:3n-3 & Control & 0.81 & 0.19 & 0.79 & 0.22 & 0.67 & 0.22 & 0.75 & 0.22 & 0.92 & 0.25 & & & \\
\hline & HFHFR & $0.22^{\star \star *}$ & 0.07 & $0 \cdot 25^{\star \star \star}$ & 0.08 & $0 \cdot 23^{\star * \star}$ & 0.07 & $0 \cdot 26^{\star \star *}$ & 0.03 & $0 \cdot 24^{\star * *}$ & 0.06 & NS & $<0.0001$ & NS \\
\hline $\mathrm{C} 20: 3 n-6$ & Control & $0.60^{\mathrm{a}}$ & 0.17 & $0.63^{\mathrm{a}}$ & 0.11 & $0.46^{\mathrm{a}}$ & 0.36 & $0.09^{\mathrm{b}}$ & 0.03 & $0.09^{\mathrm{b}}$ & 0.02 & & & \\
\hline & HFHFR & $0.63^{\mathrm{a}}$ & 0.24 & $0.74^{\mathrm{a}}$ & 0.15 & $0.23^{\mathrm{b}}$ & 0.05 & $0 \cdot 24^{\star \star \star b}$ & 0.03 & $0.26^{* \star * b}$ & 0.05 & $<0.0001$ & NS & 0.0080 \\
\hline $\mathrm{C} 20: 4 n-6$ & Control & $16 \cdot 4$ & 1.9 & $15 \cdot 6$ & $2 \cdot 8$ & $16 \cdot 2$ & 3.5 & $15 \cdot 2$ & $2 \cdot 9$ & $12 \cdot 8$ & $2 \cdot 5$ & & & \\
\hline & HFHFR & $11 \cdot 2^{\star}$ & 4.2 & $9 \cdot 76^{\star \star}$ & 3.5 & $9 \cdot 32^{\star \star}$ & $4 \cdot 1$ & $8.83^{\star \star \star}$ & 1.9 & $9 \cdot 35^{*}$ & 3.8 & NS & $<0.0001$ & NS \\
\hline C22: $6 n-3$ & Control & $3 \cdot 70^{\mathrm{a}}$ & 0.49 & $3 \cdot 36^{a, b}$ & 0.75 & $3 \cdot 52^{a, b}$ & 0.91 & $3 \cdot 33^{\mathrm{a}, \mathrm{b}}$ & 0.59 & $2 \cdot 87^{b}$ & 0.70 & & & \\
\hline & HFHFR & $2 \cdot 34^{\star \star a}$ & 0.74 & $1 \cdot 86^{\star \star a, b}$ & 0.67 & $1 \cdot 68^{\star \star a, b}$ & 0.82 & $1.49^{\star \star \star b}$ & 0.40 & $1.57^{\star * b}$ & 0.67 & 0.0380 & $<0.0001$ & NS \\
\hline UI† & Control & 159 & 8 & 155 & 9 & 158 & 11 & 158 & 10 & 148 & 8 & & & \\
\hline & HFHFR & $128^{\star \star \star}$ & 15 & $122^{\star \star \star}$ & 13 & $118^{\star \star \star}$ & 15 & $117^{\star \star \star}$ & 7 & $117^{\star \star \star}$ & 14 & NS & $<0.0001$ & NS \\
\hline$\Delta 9$-desaturase $16: 1 n-7 / 16: 0$ & Control & $0 \cdot 149^{\mathrm{a}}$ & 0.041 & $0 \cdot 169^{\mathrm{a}}$ & 0.054 & $0.200^{\mathrm{a}}$ & 0.081 & $0.210^{\mathrm{a}}$ & 0.073 & $0 \cdot 210^{\mathrm{a}}$ & 0.050 & & & \\
\hline & HFHFR & $0.029^{\star \star \star a}$ & 0.008 & $0.045^{\star \star \star b}$ & 0.011 & $0.070^{\star \star c}$ & 0.028 & $0.057^{\star \star \star b, \mathrm{c}}$ & 0.014 & $0.065^{\star \star \star c}$ & 0.017 & 0.0074 & $<0.0001$ & NS \\
\hline$\Delta 6$-desaturase $18: 3 n-6 / 18: 2 n-6$ & Control & $0.013^{\mathrm{a}}$ & 0.003 & $0.016^{a, b}$ & 0.002 & $0.017^{b}$ & 0.004 & $0.015^{\mathrm{a}, \mathrm{b}}$ & 0.003 & $0.018^{\mathrm{b}}$ & 0.001 & & & \\
\hline & HFHFR & $0.021^{\star a}$ & 0.006 & $0.017^{\mathrm{a}}$ & 0.003 & $0.016^{\mathrm{a}}$ & 0.004 & $0.015^{\mathrm{a}}$ & 0.004 & $0.017^{\mathrm{a}}$ & 0.003 & NS & NS & 0.0154 \\
\hline$\Delta 5$-desaturase $20: 4 n-6 / 20: 3 n-6$ & Control & $28 \cdot 6^{\mathrm{a}}$ & $6 \cdot 3$ & $25 \cdot 5^{\mathrm{a}}$ & $6 \cdot 12$ & $81 \cdot 2^{\mathrm{b}}$ & $75 \cdot 0$ & $156^{\mathrm{c}}$ & 49 & $155^{\mathrm{C}}$ & 46 & & & \\
\hline & HFHFR & $17 \cdot 9^{\star \star a}$ & 2.5 & $13 \cdot 3^{\star \star a}$ & 4.0 & $39.6^{\mathrm{b}}$ & 13.4 & $37 \cdot 3^{\star \star \star b}$ & 8.4 & $36 \cdot 4^{\star \star * b}$ & $12 \cdot 9$ & $<0.0001$ & $<0.0001$ & $<0.0001$ \\
\hline
\end{tabular}

HFHFR, high-fat-high-fructose; UI, unsaturation index.

All the groups were tested for the effects of diet, treatment duration and their interaction by two-way ANOVA test. When the effects of diet, treatment duration or their interaction were significant, one-way ANOVA test was applied to analyse the effect of treatment duration for each diet followed up by a Fisher's least significant difference test, and the unpaired Student's $t$ test was used to analyse the effect of HFHFR diet within each treatment duration point.

the effect of treatment duration for each diet followed up by a Fisher's least significant difference test, and the unpaired
The limit of statistical significance was set at $P<0.05$. HFHFR diet $v$. control diet: ${ }^{*} P<0.05,{ }^{* *} P<0.005, * * * 0<0.0005$

a,b,c, Inside the same diet, over treatment durations, mean values with unlike superscript letters are significantly different.

$\dagger \mathrm{UI}=(\%$ monoenoic $\times 1)+(\%$ dienoic $\times 2)+(\%$ trienoic $\times 3)+(\%$ tetraenoic $\times 4)+(\%$ pentaenoic $\times 5)+(\%$ hexaenoic $\times 6)$. 
Table 7. Relation of liver cardiolipin (CL) content in mitochondria and mitochondrial activity*

(Spearman's $\rho ; n$ 6-8 animals/group per treatment duration)

\begin{tabular}{lcc}
\hline & \multicolumn{2}{c}{$\mathrm{CL}$ (nmol/mg protein) } \\
\cline { 2 - 3 } & $\rho$ & $P$ \\
\hline Membrane potential (AU) & 0.445 & $<0.001$ \\
ROS production (AU) & -0.324 & $<0.01$ \\
Respiration (substrates + ADP) & 0.280 & $<0.05$ \\
Complex I (mU/mg protein) & 0.054 & $\mathrm{NS}$ \\
Complex II (mU/mg protein) & 0.297 & $<0.05$ \\
Complexes II + III (mU/mg protein) & 0.013 & $\mathrm{NS}$ \\
Complex IV (U/mg protein) & 0.467 & $<0.001$ \\
\hline
\end{tabular}

$\mathrm{AU}$, arbitrary units; ROS, reactive oxygen species.

* Correlations were performed with the Spearman method.

between these cited results and our results may be due to the quality of fats used in these two studies. Indeed, Bai et al. ${ }^{(26)}$ and Satapati et al. ${ }^{(27)}$ have used fat diets composed of $35 \%$ of lard only, whereas we have used a mixed fat diet (lard + palm oil + cocoa butter) to increase the saturated fatty acid percentage in our highfat diet. Moreover, it is not impossible that there is an important species difference between rat and mouse regarding installation and progression of hepatic steatosis on obesogenic diets.

It is well documented that fat intake alters mitochondrial lipid oxidation and composition, which can affect mitochondrial function and structure. Liver mitochondria play a fundamental role in the development, perpetuation and worsening of hepatic steatosis and NAFLD. Most, if not all, liver functions are dependent on energy, an ingredient that is primarily generated by the mitochondrion, the power house of all cells. Dysfunctional mitochondria lead to a shortage in ATP, a leakage of deleterious ROS and an excessive storage of fats. As mitochondria are the main producers of both cellular energy and free radicals, dysfunctional mitochondria play an important role in the development of IR and ectopic fat storage in the liver, thus supporting the emerging idea that mitochondrial dysfunction is closely related to the development of obesity, NAFLD and type- 2 diabetes mellitus. Many studies have been conducted these past 20 years to investigate the interrelation between mitochondrial dysfunction and installation and progression of NAFLD or $\mathrm{IR}^{(28,29)}$. Some of them have specifically questioned whether mitochondrial dysfunction is a cause or a direct/an indirect consequence of NAFLD or IR. These studies, carried out in rats or in mice, varied in their fat quality and quantity with or without fructose/sucrose and varied in their experiment durations and measured parameters. Some studies have concluded that mitochondrial dysfunction precedes NAFLD or $\mathrm{IR}^{(30,31)}$, whereas other studies have reported opposite conclusions or were unable to conclude ${ }^{(32)}$. Because the available literature data have still not resolved this point, we have carried out this study to re-address this question.

In our study, the ex vivo investigation of liver mitochondrial function objectivised by mitochondrial respiration and mitochondrial ROS production showed that mitochondrial respiration was decreased, whereas mitochondrial ROS production was increased throughout the study, but there was no significant difference between control and HFHFR groups at any time. However, the results of the current work showed a significant defect in mitochondrial respiratory chain complexes in the liver of obesogenic rats. Specifically, this defect was objectivised by a decreased activity of mitochondrial complexes I, II since the 12th week, whereas the decreased activity of mitochondrial complexes II + III was already observed since the 4 th week, although complex IV remained unchanged. To afford the high flux of lipid substrates to the mitochondria, the enzymatic activity of $\beta$-HAD, a crucial key in mitochondrial fatty acid oxidation, has been more than doubled in the liver of obesogenic rats since the 4th week of the study. In addition, the gene expression of Tfam, an essential protein that regulates both mitochondrial transcription initiation and mtDNA copy number, was decreased since the 8th week and continued over 12 and 16 weeks. Surprisingly, these significant alterations in mitochondrial respiratory chain complexes do not seem related to differences in the hepatic mitochondria content between obesogenic and control groups, as indicated by the similar liver CS activity and protein PGC1-a expression observed in both groups throughout the study. Our results are in agreement with previous reported defects in mitochondrial respiratory chain enzyme complexes in obesogenic rats. Garnol et al. ${ }^{(33)}$ have reported decreased activity of complex I in hepatocytes isolated from rats fed a high-fat diet compared with controls fed a standard diet. In addition, Liu et al. ${ }^{(34)}$ have reported that 12 weeks of highfat diet impaired activities of mitochondrial respiratory chain and $\beta$-oxidation in NAFLD in rats. The major part of these mitochondrial alterations nearly paralleled the installation and progression of hepatic steatosis and it seems difficult to conclude whether these alterations precede or follow the hepatic steatosis in the conditions of this experiment (online Supplementary Fig. S2).

The mitochondrial alterations observed in this study may be also originated from changes in the content and/or the composition of mitochondrial membrane phospholipids. Indeed, membrane phospholipids play multiple roles in mitochondria, acting as donors in the synthesis of macromolecules and actively influencing the functional properties of membraneassociated processes, in particular mitochondrial respiratory chain complexes ${ }^{(35)}$. Therefore, we have investigated the characteristics and the composition of mitochondrial membrane, in particular membrane potential, as well as the phospholipids and the fatty acids composition of these membranes. Indeed, mitochondrial membrane potential was nearly significantly increased (ANOVA $P=0.0561$ ) with the obesogenic diet, whereas the membrane fluidity was significantly decreased as objectivised by a significant decrease in the PC:PE ratio. It is admitted that membrane phospholipid species content and chain length of phospholipid fatty acyl chains and their unsaturation may also alter membrane fluidity. Therefore, we have investigated the mitochondrial phospholipid species content, the unsaturation and the composition of phospholipid fatty acyl chains.

Three out of six mitochondrial membrane phospholipids (PE, PI and CL) were significantly increased with the HFHFR diet, whereas total phospholipids were only non-significantly increased. Although these increases were observed since the 4 th week, these increases were all significant on the 16 th week of diet. As a consequence, the increase in PE content resulted in a decreased PC:PE ratio and thus membrane fluidity ${ }^{(36)}$. The decreased membrane fluidity may be responsible at least partly 
for the decreased activity of respiratory chain complexes. Membrane fluidity and respiratory chain complex activity are also determined by the nature of the fatty acids present in each phospholipid and their UI. Indeed, changes in membrane fatty acid composition were rapidly achieved, as soon as 4 weeks of HFHFR diet with a significant increase in SFA and MUFA and a significant decrease in PUFA. In addition, UI was lower with the HFHFR diet, resulting from lower PUFA content only partially compensated by higher MUFA content. These decreases in PC/ PE ratio and in UI should lead to a decrease in mitochondrial membrane fluidity. However, the animals can preserve structural homoeostasis through control of phospholipid synthesis, and, in particular, a previous report demonstrated that the fluidity of the mitochondrial lipid bilayer increased with CL concentration, indicating that $\mathrm{CL}$ reduced the packing of the membrane ${ }^{(7)}$. The content of $\mathrm{CL}$ in liver mitochondria was increased in the first weeks with the HFHFR diet to reach a maximal value at 12 weeks of HFHFR diet, and then returning towards the control value at 20 weeks of diet. The mitochondrial CL content was positively correlated to in vitro measures of mitochondrial membrane potential and respiration (Table 7). Thus, the increase of CL content during the 1st weeks of HFHFR diet might preserve mitochondrial bioenergetic function. In accordance with that, we and others ${ }^{(12,37,38)}$ have reported increased CL content with HFHFR diet. Increase in CL content may be driven by an increase in overall CL synthesis or a decrease in CL degradation. However, CLS gene and protein expression was lower with the HFHFR diet than the control diet, suggesting decreased CL degradation. Nevertheless, increased CLS activity to compensate for the decreased CL protein expression cannot be excluded. Therefore, CL content probably first increased with increased FA supply to the liver as an efficacious compensatory response. Then the capacity of CLS to favour synthesis of CL, even with low CLS protein expression, may be overwhelmed after 12 weeks of diet, leading to lower CL content. In fact, many studies have shown decreased CL content in diabetes and non-alcoholic steatohepatitis, advanced stage of IR and hepatic steatosis ${ }^{(39)}$. The increase in CL content with the HFHFR diet probably contributes to preserve the bioenergetic function of the mitochondria and compensates for the altered $\mathrm{PC} / \mathrm{PE}$ ratio that affects membrane properties.

\section{Conclusion}

Our results showed once again the deep interrelation between hepatic steatosis development and mitochondrial dysfunction, in particular decreased fluidity, decreased activity of certain mitochondrial respiratory complexes and increased $\beta$-HAD activity and high modulation of mitochondrial phospholipids, in particular CL content, and their fatty acid composition. Determining whether the mitochondrial dysfunction precedes or follows the hepatic steatosis is an important health issue for both prevention and treatment of this pathology. Unfortunately, based on these results it is still difficult to say whether the mitochondrial alterations preceded or followed the installation of the hepatic steatosis. Because both hepatic steatosis and mitochondrial alterations occur as early as 4 weeks of diet, future studies should consider these four 1st weeks to reveal the exact interconnection between these two major consequences of obesogenic diet intake.

\section{Acknowledgements}

The authors acknowledge the financial support of the National Institute for Agronomic Research and in particular the Human nutrition Department (Alim-H department). The authors wish also to thank the animal staff from Metamus DMEM facility which belongs to Montpellier animal facilities network (RAM, Biocampus).

Author contributions were as follows: study design and literature search: C. F.-C., S. G. and C. C., data collection: G. F., B. B., F. D., B. B., statistical analysis and manuscript preparation: (E. B., C. C. and C. F.-C., data interpretation: C. F.-C., J. L., E. B., C. C., funds collection: C. F.-C. and C. C..

The authors declare that there are no conflicts of interest.

\section{Supplementary material}

For supplementary material/s referred to in this article, please visit https://doi.org/10.1017/S0007114517003713

\section{References}

1. Barness LA, Opitz JM \& Gilbert-Barness E (2007) Obesity: genetic, molecular, and environmental aspects. Am J Med Genet A 143, 3016-3034.

2. Fromenty B, Robin MA, Igoudjil A, et al. (2004) The ins and outs of mitochondrial dysfunction in NASH. Diabetes Metab 30, $121-138$.

3. Erickson SK (2009) Nonalcoholic fatty liver disease. J Lipid Res 50, S412-S416.

4. Chiang DJ, Pritchard MT \& Nagy LE (2011) Obesity, diabetes mellitus, and liver fibreactiveis. Am J Physiol Gastrointest Liver Physiol 300, G697-G702.

5. Gauthier MS, Favier R \& Lavoie JM (2006) Time course of the development of non-alcoholic hepatic steatosis in response to high-fat diet-induced obesity in rats. BrJ Nutr $\mathbf{9 5}$, 273-281.

6. Quinn PJ (1981) The fluidity of cell membranes and its regulation. Prog Biophys Mol Biol 38, 1-104.

7. Unsay JD, Cosentino K, Subburaj Y, et al. (2013) Cardiolipin effects on membrane structure and dynamics. Langmuir $\mathbf{2 9}$, 15878-15887.

8. Paradies G, Paradies V, De Benedictis V, et al. (2014) Functional role of cardiolipin in mitochondrial bioenergetics. Biochim Biophys Acta 1837, 408-417.

9. Chicco AJ \& Sparagna GC (2007) Role of cardiolipin alterations in mitochondrial dysfunction and disease. Am J Physiol Cell Physiol 292, C33-C44.

10. Han X, Yang J, Yang K, et al. (2007) Alterations in myocardial cardiolipin content and composition occur at the very earliest stages of diabetes: a shotgun lipidomics study. Biochemistry 46, 6417-6428.

11. Petrosillo G, Portincasa P, Grattagliano I, et al. (2007) Mitochondrial dysfunction in rat with nonalcoholic fatty liver Involvement of complex I, reactive oxygen species and cardiolipin. Biochim Biophys Acta 1767, 1260-1267.

12. Aoun M, Fouret G, Michel F, et al. (2012) Dietary fatty acids modulate liver mitochondrial cardiolipin content and its fatty acid composition in rats with non alcoholic fatty liver disease. J Bioenerg Biomembr 44, 439-452. 
13. Feillet-Coudray C, Fouret G, Ebabe Elle R, et al. (2014) The mitochondrial-targeted antioxidant MitoQ ameliorates metabolic syndrome features in obesogenic diet-fed rats better than Apocynin or Allopurinol. Free Radic Res 48, 1232-1246.

14. Matthews DR, Hosker JP, Rudenski AS, et al. (1985) Homeostasis model assessment: insulin resistance and b-cell function from fasting plasma glucose and insulin concentrations in man. Diabetologia 28, 412-419.

15. Folch J, Lees M \& Sloane Stanley GH (1957) A simple method for the isolation and purification of total lipides from animal tissues. J Biol Chem 226, 497-509.

16. Aoun M, Feillet-Coudray C, Fouret G, et al. (2011) Rat liver mitochondrial membrane characteristics and mitochondrial functions are more profoundly altered by dietary lipid quantity than by dietary lipid quality: effect of different nutritional lipid patterns. Br J Nutr 107, 647-659.

17. Bradford MM (1976) A rapid and sensitive method for the quantitation of microgram quantities of protein utilizing the principle of protein-dye binding. Anal Biochem 72, 248-254.

18. Barja $\mathrm{G}$ (2002) The quantitative measurement of $\mathrm{H}_{2} \mathrm{O}_{2}$ generation in isolated mitochondria. J Bioenerg Biomembr 34, 227-233.

19. Clayton PT, Eaton S, Aynsley-Green A, et al. (2001) Hyperinsulinism in short-chain L-3-hydroxyacyl-CoA dehydrogenase deficiency reveals the importance of $\beta$-oxidation in insulin secretion. J Clin Invest 108, 457-465.

20. Bartlett GR (1959) Phosphorus assay in column chromatography. J Biol Chem 234, 466-468.

21. Lepage G \& Roy CC (1986) Direct transesterification of all classes of lipids in a one-step reaction. J Lipid Res 27, 114-120.

22. Warensjo E, Riserus U, Gustafsson IB, et al. (2008) Effects of saturated and unsaturated fatty acids on estimated desaturase activities during a controlled dietary intervention. Nutr Metab Cardiovasc Dis 18, 683-690.

23. Green CJ \& Hodson L (2014) The influence of dietary fat on liver fat accumulation. Nutrients 6, 5018-5033.

24. Arendt BM, Ma DW, Simons B, et al. (2013) Nonalcoholic fatty liver disease is associated with lower hepatic and erythrocyte ratios of phosphatidylcholine to phosphatidylethanolamine. Appl Physiol Nutr Metab 38, 334-340.

25. Ferramosca A, Conte A, Burri L, et al. (2012) A krill oil supplemented diet suppresses hepatic steatosis in high-fat fed rats. PLOS ONE 7, e38797.

26. Bai XP, Li HL, Yang WY, et al. (2010) Sequence of fat partitioning and its relationship with whole body insulin resistance. Chin Med J (Engl) 123, 3605-3611.
27. Satapati S, Sunny NE, Kucejova B, et al. (2012) Elevated TCA cycle function in the pathology of diet-induced hepatic insulin resistance and fatty liver. J Lipid Res 53, 1080-1092.

28. Rogge MM (2009) The role of impaired mitochondrial lipid oxidation in obesity. Biol Res Nurs 10, 356-373.

29. Dumas JF, Simard G, Flamment M, et al. (2009) Is skeletal muscle mitochondrial dysfunction a cause or an indirect consequence of insulin resistance in humans? Diabetes Metab 35, 159-167.

30. Kahle M, Schafer A, Seelig A, et al. (2015) High fat dietinduced modifications in membrane lipid and mitochondrialmembrane protein signatures precede the development of hepatic insulin resistance in mice. Mol Metab 4, 39-50.

31. Rector RS, Thyfault JP, Uptergrove GM, et al. (2010) Mitochondrial dysfunction precedes insulin resistance and hepatic steatosis and contributes to the natural history of non-alcoholic fatty liver disease in an obese rodent model. J Hepatol 52, 727-736.

32. Flamment M, Rieusset J, Vidal H, et al. (2012) Regulation of hepatic mitochondrial metabolism in response to a high fat diet: a longitudinal study in rats. $J$ Physiol Biochem 68, 335-344.

33. Garnol T, Endlicher R, Kucera O, et al. (2014) Impairment of mitochondrial function of rat hepatocytes by high fat diet and oxidative stress. Physiol Res 63, 271-274.

34. Liu X, Zhang J, Ming Y, et al. (2015) The aggravation of mitochondrial dysfunction in nonalcoholic fatty liver disease accompanied with type 2 diabetes mellitus. Scand J Gastroenterol 50, 1152-1159.

35. Dowhan W (1997) Molecular basis for membrane phospholipid diversity: why are there so many lipids? Annu Rev Biochem 66, 199-232.

36. Tepsic V, Ristic V, Ristic D, et al. (1998) Heart phospholipid content and fatty acid composition in the rat after feeding different lipid supplemented diets. Physiol Res $\mathbf{4 7}$, 413-418.

37. Fouret G, Tolika E, Lecomte J, et al. (2015) The mitochondrialtargeted antioxidant, MitoQ, increases liver mitochondrial cardiolipin content in obesogenic diet-fed rats. Biochim Biophys Acta 1847, 1025-1035.

38. Stavrovskaya IG, Bird SS, Marur VR, et al. (2013) Dietary macronutrients modulate the fatty acyl composition of rat liver mitochondrial cardiolipins. J Lipid Res 54, 2623-2635.

39. Feillet-Coudray C, Fouret G, Casas F, et al. (2014) Impact of high dietary lipid intake and related metabolic disorders on the abundance and acyl composition of the unique mitochondrial phospholipid, cardiolipin. J Bioenerg Biomembr 46, 447-457. 